\title{
Review Article \\ Tumour Immunogenicity, Antigen Presentation, and Immunological Barriers in Cancer Immunotherapy
}

\author{
David Escors ${ }^{1,2}$ \\ ${ }^{1}$ Navarrabiomed-Fundacion Miguel Servet, Calle Irunlarrea n 3, Complejo Hospitalario de Navarra, 31008 Pamplona, Navarra, Spain \\ ${ }^{2}$ Rayne Institute, University College London, 5 University Street, London WC1E 6JF, UK \\ Correspondence should be addressed to David Escors; d.escors@ucl.ac.uk
}

Received 7 August 2013; Accepted 17 September 2013; Published 5 January 2014

Academic Editor: Maria Chiara Maiuri

Copyright (C) 2014 David Escors. This is an open access article distributed under the Creative Commons Attribution License, which permits unrestricted use, distribution, and reproduction in any medium, provided the original work is properly cited.

\begin{abstract}
Since the beginning of the 20th century, scientists have tried to stimulate the antitumour activities of the immune system to fight against cancer. However, the scientific effort devoted on the development of cancer immunotherapy has not been translated into the expected clinical success. On the contrary, classical antineoplastic treatments such as surgery, radiotherapy, and chemotherapy are the first line of treatment. Nevertheless, there is compelling evidence on the immunogenicity of cancer cells and the capacity of the immune system to expand cancer-specific effector cytotoxic T cells. However, the effective activation of anticancer T cell responses strongly depends on efficient tumour antigen presentation from professional antigen presenting cells such as dendritic cells (DCs). Several strategies have been used to boost DC antigen presenting functions, but at the end cancer immunotherapy is not as effective as would be expected according to preclinical models. In this review, we comment on these discrepancies, focusing our attention on the contribution of regulatory $\mathrm{T}$ cells and myeloid-derived suppressor cells to the lack of therapeutic success of DC-based cancer immunotherapy.
\end{abstract}

\section{Introduction: Vaccines Infectious Diseases and Cancer}

Not so long ago, I had a conversation with a colleague of mine about our differing research interests. He asked me why I was so much interested in cancer research and not that keen on infectious diseases. This particular question made me think about my motives for working in cancer research. Cancer is in many cases an "adult" noncontagious disease (with exceptions), while infectious diseases can attack anyone at any time. In addition, infectious agents are highly contagious and new ones arise from time to time $[1,2]$. He argued that compared to cancer, infectious diseases are a much higher health burden worldwide. After this conversation I quickly looked at the statistics and according to Cancer Research UK (http://www.cancerresearchuk.org), there were about 7.6 million deaths from cancer in 2008. Then I looked at the deaths caused by infectious diseases, and according to the World Health Organisation (WHO, http://www.who.int/en/) about 13 million deaths (of all ages) were caused by infectious diseases in 1998. Even though the data was not that recent,
I concluded that the first premise on health burden might not be completely accurate. However, ultimately that was not the reason I was looking for. Therefore, why is cancer so fascinating that attracts so much scientific and medical efforts?

Among the nonmedical community in the "developed" world, infectious diseases are not the problem they historically used to be, apart from some exceptions such as AIDS. We owe this to the introduction of hygiene measures and sanitation, which are possibly more significant factors than vaccines in controlling "everyday" infections. Nevertheless, there is no doubt in the medical community that mass vaccination is an effective way of achieving population immunity, essential for the eradication of infectious agents $[3,4]$. It is worthy to mention that the overall population has in some cases forgotten the importance of mass vaccination for the most common infectious agents. This is a well-known phenomenon denominated "vaccine refusal" and has serious consequences that delay the eradication of infectious diseases [5]. As a recent example of this, there was an important measles virus outbreak in England in 2012. This outbreak with 
serious consequences in a proportion of infected children was caused by "vaccine refusal" for the triple measlesmumps-rubella vaccine due to fears from unfounded links with autism [6-8]. Therefore, good-intentioned nonrational decisions made by following inaccurate perceptions have a real significant impact on the population's health status and the propagation of infectious diseases.

However, cancer is a different matter. There is not any doubt in my mind that anyone would vaccinate their children against cancer. Why is that so? Well, on one hand the longer that we live, the higher the chances of suffering from some type of cancer. Secondly, cancer will quickly kill the patient without much that modern medicine can do to prevent it. Thirdly, radiotherapy and chemotherapy cause severe secondary effects, and in many cases they will prolong life but not cure cancer.

So, this is from the point of view of the population. However, why is it so fascinating for scientists? Well, for me, the answer lies in the scientific challenge itself. Cancer arises from the complications caused by the uncontrolled growth of transformed cells (tumours). It would not be such a problem, as tumours can be removed by surgery. However, if left untreated, these cells will eventually colonise the organism through a process called metastasis. The establishment of secondary tumours from these cancer cell colonies significantly interferes with the physiological functions of the organism. And here is where the challenge lies. These cells come from self-tissues, and therefore, the immune system is largely tolerant to them. In the case of infectious diseases, viral and bacterial products are "foreign" or "non-self", so it is relatively easy for immune cells to detect them and get rid of the infectious agents. That is why the development of vaccines against infectious diseases is relatively straightforward in comparison to cancer vaccines. In the case of cancer, how can we alert the immune system against mutated "self-cells"? Does it really play a role in controlling cancer?

\section{Tumour Antigenicity}

At the beginning of the 20th century, Paul Ehrlich put forward the tumour immunosurveillance theory. He had already worked in the role of immune responses to control infections caused by microorganisms. He then applied the same observations to cancer. He proposed that cancer cells spontaneously arise in the organism and that immune responses could effectively eliminate them [9]. This same concept was later refined by Burnet [10]. The fast development of organic chemistry, biochemistry, and molecular biology (and nuclear physics!) that followed in the 20th century provided the tools to systematically study cancer and develop chemotherapeutic agents that could inhibit cancer cell growth [11]. For the first time, drugs could be developed that were effective to at least control (and in some cases cure in combination with surgery and radiotherapy) cancer. Therefore, biomedical research directed its efforts in the development of these new drugs. The study of anticancer immune responses steadily continued, but it never reached a therapeutic status as achieved by other "conventional" methods. The lack of success of cancer vaccines led to another misconception which still lingers within a relatively large proportion of the scientific community; immune responses did not play a significant role in controlling cancer, unlike "classical" antineoplastic strategies such as radiotherapy and chemotherapy. Interestingly, there is strong recent evidence that classical anticancer treatments heavily rely on the immune system for their effectiveness [12-20]. These treatments include radiotherapy and chemotherapy and depend on cellular stress responses [17]. These responses lead to enhanced antitumour activities through the activity of TLR agonists released from necrotic tumour cells and activation of the inflammasome in antigen presenting cells by released ATP $[14,15]$. Interestingly, these conventional antineoplastic treatments lose their efficacy when immunocompromised mice are used in the experiments, or when human patients have deleterious mutations on TLR4 [14].

What determines whether cancer vaccines can become a success in human immunotherapy? Exactly the same as required for infectious diseases, cancer has to be immunogenic and activate cytotoxic $\mathrm{T}$ cell responses. Consequently, cancer cells have to possess immunogenic antigens susceptible of being targeted by vaccination.

Since Ehrlich's proposal, researchers have been looking for tumour-associated antigens (TAAs) that could be exploited for cancer immunotherapy. And even though early studies found some experimental evidence towards their existence (particularly from virus-induced tumours), the problem of the immunological tolerance always came back for the counterattack [21-26]. Many of these studies concentrated on immune responses against virus-induced tumours rather than endogenous cancer antigens [24, 27-29]. In fact, at the time there was an increasingly accumulating body of evidence supporting the viral aetiology of nearly all human cancers [30-32]. This resulted in a major (slightly misguided?) change of view for cancer therapy, as it was much easier to target foreign viral antigens expressed by tumour cells than mutated self-antigens [30, 33-35]. Now we know that only a number of human cancers are caused by viral infections. Nevertheless, the "viral aetiology" theory for human cancer could not explain the immune responses against chemically induced cancers that were also observed. However, in many instances these results could not be reproduced by other research groups [36]. Even so, these early studies provided evidence that immune responses could be raised against tumours of nonviral origin. Spontaneous tumour regressions were also sporadically observed in human patients, in some cases provoked after immunisation towards common pathogens, strongly supporting the existence of TAAs of nonviral origin $[20,37,38]$.

A turning point came from the study of oncogenic viruses, especially from the Retroviridae family which led to a "shocking" discovery. These viruses induced cancer through the expression of oncogenes, which had their corresponding cellular variants [39-47]. These oncogenes included v-raf, c-my, c-rel, and k-ras among others. All these proteins were largely involved in the regulation of cell proliferation and survival. So after all, transforming oncoviruses had "hijacked" cellular oncogenes for their own advantage. But, in cancers of nonviral aetiology, are the corresponding cellular versions involved in carcinogenesis? 
That turned out to be the case [48]. Cancerous cells accumulate a series of mutations leading to genetic instability, which results in protein expression changes, increased survival, and uncontrolled proliferation [47-52]. Many of the mutated proteins were transcription factors (c-myc), part of key signalling pathways (human Ras), cell cycle regulators (retinoblastoma protein, $\mathrm{Rb}$ ), and antioncogenes (p53). As a result of uncontrolled proliferation and defects in DNA repair/apoptosis pathways, further mutations and chromosomal rearrangements appear. "Fortunately", as a direct consequence, these cells express a collection of mutated self-proteins that confers them with a degree of immunogenicity (quasi-antigens). In some cases, self-proteins can be aberrantly overexpressed in tumours, which would not normally be expressed in the corresponding healthy tissue. This acquired immunogenicity allows the immune system to identify and destroy them.

\section{Identification of Human TAAs}

Evidence for the existence of immunogenic autologous tumour antigens appeared about 50-60 years ago [35], and since then an increasingly growing collection of TAAs has been identified [53]. It is not the intention of this review to provide an extensive and detailed list of the TAAs that have been identified so far. However, it is worthy to mention the most widely used in human therapy and how they were discovered.

In the 1950s, tyrosinase overexpression in melanomas had already been observed $[54,55]$. Tyrosinase is an oxidase involved in melanin production which is specifically expressed in melanocytes. Interestingly, it was shown to be immunogenic and tyrosinase-specific CD8 T cells could lyse melanoma cell lines [56, 57]. In 1994, CD4 T cells were demonstrated to recognise HLA-DR-specific tyrosinase peptide epitopes [58]. Tyrosinase-derived peptides have been used in vaccines against melanoma, alone or in combination with other TAAs $[59,60]$.

Carcinoembryonic antigens (CEA) were indirectly identified in the 1960s, by the detection of anti-CEA antibodies in human colon cancer patients $[61,62]$. CEA is a cell adhesion glycoprotein of the immunoglobulin superfamily which is expressed during foetal development [63]. Interestingly, CEA is again reexpressed especially in colorectal cancer, although it can also be expressed in many other carcinomas [6367]. This expression pattern made it a good candidate for immunotherapy. In 1995-1996, CEA-specific T cell responses were demonstrated, and a CEA-derived immunogenic $\mathrm{T}$ cell peptide was identified $[68,69]$. From then on, several different CD8- and CD4-restricted peptide epitopes have been found and used in human immunotherapy [70-75]. Licensed CEA-based vaccines are extensively used in many variations of cancer immunotherapy [76]. There is strong evidence supporting the role of anti-CEA $\mathrm{T}$ cell responses in breaking immunological tolerance towards other tumour antigens.

Alpha-fetoprotein (AFP) was reported to be expressed in some tumours in the 1970s [77]. AFP is a globulin-like plasma protein present at high levels during foetal development, and it is elevated particularly in hepatic cancers [78, 79]. AFP is currently used as a tumour marker rather than an immunotherapy target, because it strongly inhibits $\mathrm{T}$ cell responses [80]. Nevertheless, immunogenic $\mathrm{T}$ cell epitopes have also been identified [81-85] that could be used as targets in cancer vaccines, alone or in combination with other TAAs $[86,87]$.

The cancer antigen 125 (CA-125), highly expressed in ovarian carcinomas, was discovered in 1981 by the specific reactivity of the murine $\mathrm{OC} 125$ monoclonal antibody towards ovarian carcinoma cell lines $[88,89]$. CA-125 is a glycoprotein belonging to the mucin family, which is generally immunosuppressive and correlates with tumour progression. There is evidence that immune responses can be raised against CA-125 that could be therapeutically relevant [90-92].

In the 1980s, elevation of prostate-specific antigen (PSA) was observed in prostate hyperplasia and cancer [93, 94]. PSA is a peptidase expressed by epithelial cells of the prostate gland, and it has been classically used as a tumour maker although its reliability has been questioned. PSA has also been used in cancer immunotherapy as a prostate cancer vaccine [95-97], and immunogenic T cell epitopes have also been described for it [98-101].

The melanoma-associated antigens (MAGE antigens, cancer-testis antigens), also expressed by a wide variety of cancers $[102,103]$, were described in the early 1990s and shown to contain many immunogenic $\mathrm{T}$ cell peptide epitopes [104-110]. MAGE antigens are also big players in the development of cancer vaccines. They have been successfully applied in human immunotherapy protocols leading to melanoma regression, and their use can also break tolerance towards other TAAs such as gp100 [111].

Also in the 1990s, the immunogenic tyrosinase-related proteins 1 and 2 (TRP-1, TRP-2) were cloned. Both of them are frequently overexpressed in melanoma [112-114]. CD8 and CD4 T cell epitopes have also been identified for these TAAs, especially for the "highly immunogenic" TRP-2 protein [115-121]. TRP-1 is a TAA of interest in human therapy although not one of the most immunogenic melanomaassociated antigens $[122,123]$. Interestingly, the use of selectively mutated TRP1 CD8 T cell epitopes can effectively break immunological tolerance and drive effective antimelanoma responses [120]. TRP-2-targeted immune responses can also lead to melanoma regression $[124,125]$.

The gp100 protein was identified in 1988 by its reactivity with a melanocyte lineage-specific monoclonal antibody used for diagnosis of human melanoma [126]. It was later cloned and demonstrated that human cytotoxic T cells could recognise immunogenic gp100 epitopes [117, 127, 128]. This particular TAA is extensively used in the development of melanoma vaccines [59].

In 1997, NY-ESO-1 (cancer-testis antigen 1B) was isolated from esophageal squamous cell carcinoma, and immune responses demonstrated in humans against it $[129,130]$. NYESO-1 is also expressed by a wide range of cancers, including ovarian cancer, melanoma, sarcomas, neuroblastoma, leukaemias, and lymphomas, just to name a few. Several CD8 and CD4 T cell epitopes have been defined which are relevant to trigger anti-cancer immune responses [131-135]. 
NY-ESO-1 is possibly one of the best antigens for human immunotherapy due to its wide expression patterns and immunogenicity [136-138]. T cells modified to express NYESO-1-specific TCRs were shown to induce tumour regression in metastatic synovial cell sarcoma and melanoma [139].

MART-1/Melan A was cloned in 1994 from a HLA-A2+ melanoma cell line-derived cDNA library by transfection into target cells for lysis by established melanoma-specific cytotoxic T cells [140]. MART-1-specific TCRs were identified from human patients shortly after and shown to be specific to a HLA-A2-specific MART-1 peptide epitope [141]. Again, MART-1 is extensively used together with other TAAs for vaccination against melanoma $[59,60,134]$. In fact, there is evidence suggesting that the activities of MART-1-specific CD8 $\mathrm{T}$ cells are prominent in effective immunotherapy for melanoma [142]. Genetically engineered autologous CD8 T cells for the expression of MART-1-specific TCRs demonstrated their capacities to achieve melanoma regression and long-term cures in animal models and human patients [143145].

Summarising, cancer cells are in fact immunogenic, and they are not immunologically silent. There is a wide range of common TAAs expressed in a range of cancers which raise both CD4 and CD8 T cells. In fact, there are numerous studies both in preclinical experimental models and in human clinical trials that report effective $\mathrm{T}$ cell responses. However, overall, the clinical success of cancer immunotherapy is rather low even though TAA-specific autologous $\mathrm{T}$ cells can be expanded. In fact, these $\mathrm{T}$ cells exert good cytotoxic activities ex vivo and can mediate strong tumour regression in vivo. But at the end, long-term cures are infrequent and tumours usually come back by escaping from the immune system using a variety of mechanisms. Some of these mechanisms involve the selection of cancer cell variants that lose TAA expression or decrease the expression of MHC molecules. In this review, the involvement of regulatory immune cells that expand in cancer and strongly inhibit anticancer immune responses will be discussed.

\section{Concept and Application of Cancer Immunotherapy}

As we have discussed above, cancer cells express many TAAs that in some cases appear in a wide range of cancers with relatively high frequency. However, the presence of potentially immunogenic TAAs does not directly answer the question on whether the immune system plays a central role in controlling cancer in physiological conditions, in other words, whether the immune system is competent in protecting the organism against cancer in the absence of external interventions. If the immune system would in fact be competent, then strategies to boost its natural anti-neoplastic activities could succeed for human therapy. How to prove whether the "cancer immunosurveillance" hypothesis has any basis?

Compelling evidence on the role of the immune system in keeping potential cancer cells at bay when they arise in the organism came in 2001, by the observation of cancer immunoediting [146]. Several research groups noticed that cancers growing in immunodeficient mice were by far more immunogenic than the same cancers grown in immunocompetent mice [20]. When $\mathrm{T}$ cell responses were raised against these tumours, their regression was apparent, but some cancer cells escape from the immune system. These escapees had lost immunogenicity, demonstrating that the immune system is exerting at all times a selective pressure. In the absence of immune responses, tumours are immunogenic. In the presence of competent immune responses, less immunogenic tumours are selected out of the immune pressure.

Nowadays, a four-stage process for oncogenesis is widely recognised by tumour immunologists: (1) transformation of cancerous cells, (2) raising of anti-cancer immune responses, (3) establishment of a cancer growth-immune attack equilibrium which exerts a selective pressure, and (4) immunological escape of poorly immunogenic cancer cells.

To succeed against cancer, it is necessary to strongly boost step 2, while reducing at maximum the establishment of cancer-immune system equilibrium. In a "natural" anticancer immune response, there is clearly amplification of TAA-specific effector T cells. However, this amplification is much smaller than that found in $\mathrm{T}$ cell responses against infectious agents. TAA-specific T cells are usually of low affinity or even anergic. An antitumour attack of a limited number of these effector $\mathrm{T}$ cells will shift the equilibrium balance towards selection of escaping cancer cells. For effective anticancer therapies, the amplification of a very large number of effector $\mathrm{T}$ cells is necessary to culminate in a "blitz" attack leaving no chance for immune escape (Figure 1). So, antitumour $\mathrm{T}$ cell responses need to reach a critical mass to be effective. We recently proposed this mechanism based on our experimental observations, the critical mass hypothesis of $\mathrm{T}$ cell responses [147-149] (Figure 1).

Therefore, the main objective of cancer immunotherapy is to strongly stimulate the immune system through a variety of procedures to boost the natural anti-tumour immunity or to implement novel antitumour properties to immune cells by, for example, genetic modification. Cancer immunotherapy groups a variety of techniques directed to increase the activities of T, B and dendritic cells (DCs) to raise strong anti-tumour immune responses. The manipulation of these cell types is carried out by conventional techniques such as the use of vaccine adjuvants together with TAAs, cytokine/chemokine therapies or by molecular/genetic techniques [148, 150-155]. Some successful examples of these procedures are the expression in T cells of TAA-specific T cell receptors (TCRs) and chimeric antigen receptors (CARs) directed towards tumour antigens $[139,145,156,157]$ or the administration of TAA-loaded DCs [158]. Nevertheless, for any successful cancer immunotherapy, it is imperative to achieve a strong, effective TAA presentation to effector cytotoxic cells, especially CD8 T cells [159].

Cancer immunotherapy depends on the enhancement of potent cytotoxic $\mathrm{T}$ cell (CTL) responses against TAAs. Antigens are processed into a series of antigenic peptides which are loaded into MHCs. These peptide-MHC complexes are exposed on the surface of both antigen presenting cells (APCs) and also normal and transformed cells. While antigen presentation by APCs will lead to the activation of effector 


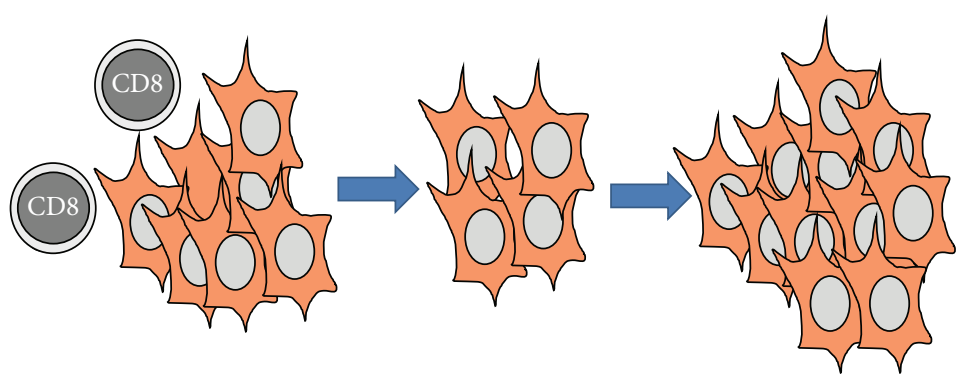

(a)
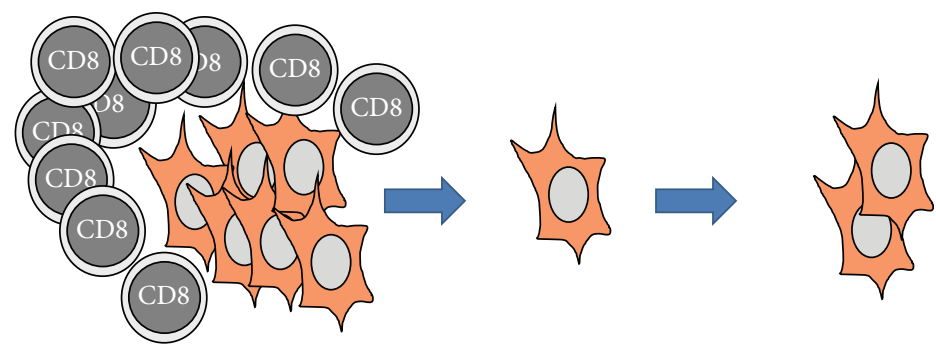

(b)

Figure 1: A critical mass of TAA-specific cytotoxic T cells is necessary to reduce immunological editing and cancer escape. (a) A tumour mass represented as a group of transformed cells (orange) is being attacked by a limited number of TAA-specific T cells (left). Immunological editing takes place as indicated above the arrow, due to limited and slow killing of TAA-expressing T cells leaving a significant number of poorly immunogenic cancer cells alive (centre). These cells eventually regrow through reduced immunogenicity and lack of CD8 T cell attack (right). (b) The same situation as in (a) with the difference that a large pool of TAA-specific cytotoxic CD8 T cells has expanded following immunotherapy (left). In this way, a larger number of cancer cells will be killed in the tumour mass, leaving no cells or a very reduced number of them alive. This situation will minimise immunological editing and cancer escape (centre). At the end, as turns out in many cancer immunotherapy treatments, the tumours usually come back. However, in comparison with the situation shown in (a), it will take longer to the tumour to regrow with an associated increase in survival.

$\mathrm{T}$ cells, their presentation on the surface of normal cells discriminates normal, healthy cells from infected, transformed cells. Briefly, antigen-specific T cells expanded by APCs will look for cells exposing their corresponding antigenic peptide$\mathrm{MHC}$ complexes. Once they are found, T cells will exert their cytotoxic activity and eliminate infected/transformed cells.

$\mathrm{T}$ cells recognise their cognate antigenic peptides and activate by direct binding of their TCR to peptide-MHC complexes present on the surface of APCs (Figure 2). This recognition delivers a signal to $\mathrm{T}$ lymphocytes, which is insufficient to effectively activate them. Antigen-presenting APCs have to provide additional signals in the immunological synapse to the $\mathrm{T}$ cell [153]. These cosignals will regulate the degree of $\mathrm{T}$ cell activation and can be stimulatory or inhibitory [160]. A major costimulatory interaction takes place after the binding of CD80 on APCs with CD28 on T cells. However, an array of inhibitory interactions also occurs in the immunological synapse, such as binding of CD80 with CTLA4 or PD-L1 with PD1 [153, 161]. The integration between positive and negative costimulation will determine the degree of $\mathrm{T}$ cell activation [160] (Figure 2). In addition to these two signals, the specific cytokine profile produced during the DC-T cell engagement will drive $\mathrm{T}$ cell differentiation towards CD4 T helper (Th) subtypes [153]. These different responses can be proinflammatory, such as those driven by Th1, Th17, antibody responses controlled by Th2, or immune suppression as regulated by regulatory $\mathrm{T}$ cell differentiation.
While responses against infectious agents are usually strong and specific, as they rely upon the recognition of pathogen-derived molecules by APCs such as DCs, this is not the case with anti-cancer responses. Activation of TAAspecific $T$ cells can be certainly challenging. Firstly, TAAs can be expressed at low concentrations, leading to suboptimal antigen presentation. In this situation, $\mathrm{T}$ cells that recognise antigen-presenting cells (in minute concentrations) differentiate towards Tregs $[162,163]$. On the other hand, it is well known that $\mathrm{T}$ cells can be efficiently activated by the engagement of a low number of peptide-MHC complexes by a process called "serial TCR triggering" $[148,155]$. It has to be taken into account that most p-MHC complexes bind TCRs with low affinities anyway, and co-stimulation plays the part of strengthening TCR-pMHC binding. However, TCR manipulation by genetic engineering can increase signal 1 leading to effective cancer immunotherapy in animal models and human clinical trials [164].

Engagement of DCs with pathogen-derived molecules causes DC maturation by upregulation of co-stimulatory signals, MHC molecules and secretion of pathogen-specific cytokine profiles [154]. Then, maturing DCs migrate to secondary lymphoid tissues and present pathogen-derived antigens to specific T cells. However, in the case of cancer, TAAs are frequently aberrantly overexpressed endogenous proteins or quasi-antigens. A major problem for anti-cancer immune responses is that the frequency of TAA-specific $\mathrm{T}$ 


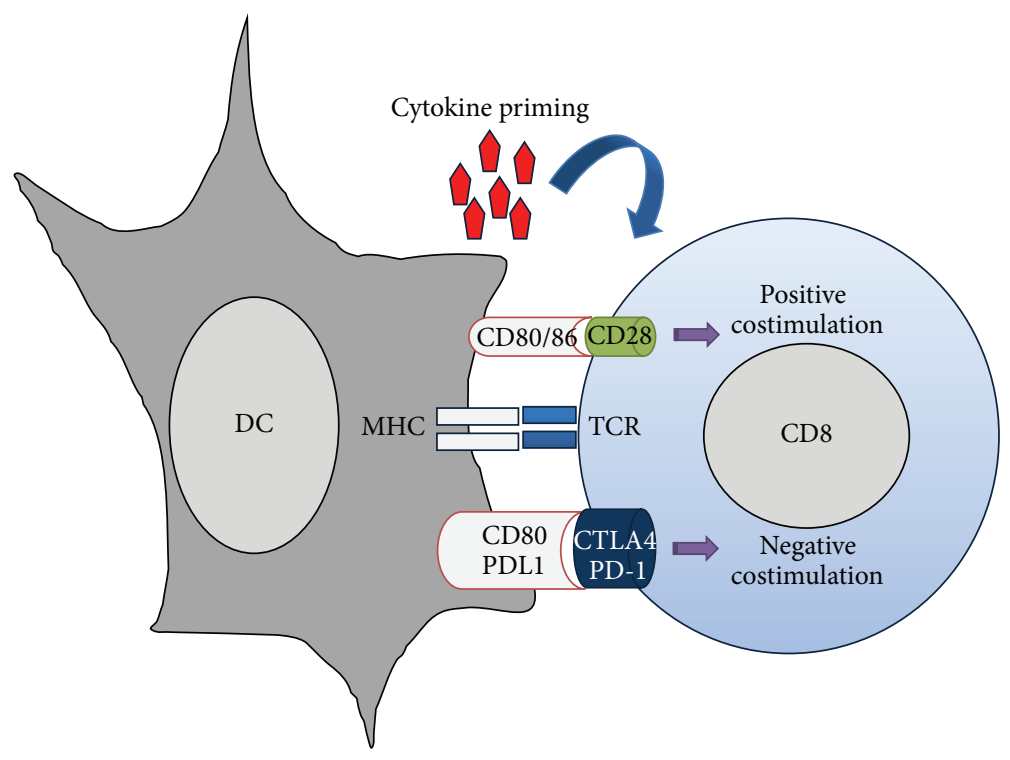

FIGURE 2: T cell activation by antigen presentation. Tumour antigen presentation to $\mathrm{T}$ cell by dendritic cells (DC, on the left) is schematically depicted in this picture. The antigenic peptide complexed to the MHC, as indicated within the DC on the left, is recognised by the TCR on the T cell surface, as indicated within the T cell on the right. To effectively activate TAA-specific T cells, strong costimulation is needed. Costimulation depends on the integration between activatory (positive, as indicated on top of the MHC-TCR interaction) and inhibitory (negative, as indicated below the MHC-TCR interaction) bindings between ligands on the DC cell with their corresponding receptors on the T cell. For effective T cell activation and acquisition of effector activities, a third signal is necessary, provided by cytokines present in the immunological synapse, as indicated on top.

cells is generally low, as they are removed by clonal deletion in the thymus. The circulating autoreactive T cells that escaped from clonal deletion possess low-affinity TCRs or had already differentiated into natural Tregs in the thymus [165].

\section{Dendritic Cell-Based Cancer Immunotherapy}

As already discussed throughout this review, there are many immunotherapeutic approaches for the treatment of cancer. Here, we will briefly focus on the use of DCs for cancer immunotherapy, since a significant research effort has been dedicated for the therapeutic targeting of DCs. Steinman and Cohn discovered conventional DCs in 1973 [166]. These cells were found to be the most potent activators of $\mathrm{T}$ cell responses [167] but also strong inhibitors when not appropriately activated $[168,169]$. Dendritic cells comprise a heterogeneous group of cell types derived from haematopoietic precursors. They are frequently classified in two broad groups according to their lineage, myeloid (or conventional) DCs and plasmacytoid DCs [13]. A major breakthrough occurred about twenty years ago when conventional DCs were shown to efficiently differentiate ex vivo from mouse bone marrow using GM-CSF. Four years later, the corresponding DC production method from human monocytes was published, using a combination of GM-CSF and IL4 [170, 171]. The possibility of their ex vivo expansion significantly stimulated DC-based immunotherapy, due to the high reproducibility of these procedures and their ease of use. In addition, no previous specific knowledge on the particular antigenic peptide epitopes for a given antigen was required. DCs could efficiently take up any antigen and process it for antigen presentation (Figure 3). Or even the specific HLA genotype of the patient, as autologous DCs could be differentiated, loaded ex vivo with antigen and reintroduced into the patient. In addition, DC numbers were not a limiting factor any more. Around 50 million DCs can be reproducibly obtained from a single mouse's bone marrow in one week. From PBMCs, large numbers of DCs can still be obtained, although for human therapy the procedure is slightly more cumbersome as blood has to be taken in high quantities from patients [172]. These cultured DCs are immature, and this ensures that they can be modified and matured using the required stimuli for immunotherapy $[154,173,174]$. The efficient cell yields have allowed the systematic characterisation of a wide variety of immunostimulatory/inhibitory treatments (Figure 3). As one of the key problems of cancer immunotherapy is the effective activation of TAA-specific effector T cells, DC vaccination might be one of the best immunotherapeutic strategies. The enhancement of their potent antigen-presenting strategies might be sufficient to strongly activate low-affinity effector $\mathrm{T}$ cells and break the natural tolerance towards endogenous TAAs.

DCs present on their surface a wide collection of receptors which recognise a variety of pathogen-associated molecular patterns or inflammation-related cellular proteins. The binding of these molecules with their appropriate receptors triggers their phenotypic and function maturation, by the strong upregulation of MHC and costimulatory molecules of antigen presentation (Figure 2). The ability to grow ex vivo large quantities of DCs has allowed the detailed study of cellular and molecular mechanisms of antigen presentation to T cells [153]. 


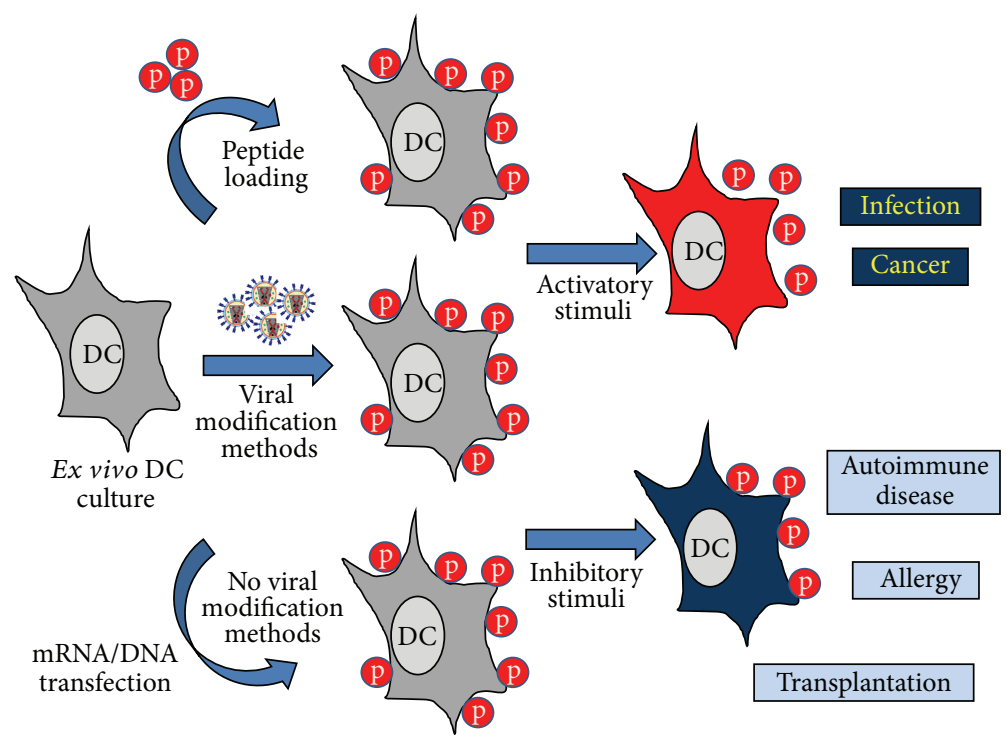

FIGURE 3: Ex vivo manipulation of DCs for immunotherapy. This figure schematically represents the manipulations performed with murine or human ex vivo-generated DCs for immunotherapy. DC cultures grown for about 5-10 days (left of the figure) are treated to present antigens of interest. This can be carried out by either direct peptide loading on DC cultures, as indicated by the top arrow, by genetic manipulation using viral vectors expressing the antigens of interest (central arrow), or by nonviral genetic manipulation using mRNA/DNA electroporation or transfection (bottom arrow). Any of these procedures will end up with DCs presenting the antigenic peptides in their surface associated to MHC molecules (represented as spheres labelled with a "p"). After that, the maturation stage and functional properties of the modified DCs can be manipulated by incubation with either stimulatory, as indicated by the top arrow on the right, or inhibitory stimuli, as indicated by the bottom arrow. These stimuli can be TLR agonists or antagonists, cytokines, chemokines, chemotherapy drugs, and even achieved by genetic manipulation. Pro-inflammatory DCs (DCs in orange) presenting antigenic peptides can be used for the treatment of infectious diseases and cancer, as indicated on the right by the text boxes. On the other hand, inhibitory (tolerogenic) DCs can be applied as immunosuppressive agents for the treatment of disorders and transplantation, as indicated by the text boxes.

Obviously, the large-scale DC production was quickly applied for immunotherapy and vaccination, particularly to achieve the strong antigen presentation that was required to stimulate effective anti-tumour immune responses. Immature cultured DCs can be incubated with antigens, which are phagocytosed, processed into antigenic peptides, and loaded onto MHC molecules (Figure 3). These antigens can also be TAAs, either as peptides or directly from tumour lysates [13]. Another advantage is that ex vivo differentiated immature DCs can be genetically modified with a variety of viral vectors including adenovirus, retrovirus, lentivirus, or poxvirus or even with nonviral methods such as mRNA electroporation $[13,154,175,176]$. As their maturation state can also be controlled using appropriate adjuvants or even molecular activators/inhibitors $[12,134,149,176,177]$, they are ideal for immunotherapy (Figure 3). Consequently, ex vivo generated DCs have been used to raise $\mathrm{T}$ cell responses to infectious agents [178-182] and in cancer immunotherapy $[134,149,183-188]$. They have also been used as tolerising agents for autoimmune disorders in experimental animal models and in human therapy $[168,169,189-194]$ (Figure 3).

Most of the preclinical research in immunotherapy using ex vivo DCs has provided relevant data [13, 158, 195-197]. However, these results have not always been translated into the expected clinical success in human cancer immunotherapy $[159,198,199]$. Why is that so? To try to answer this question, our research group has been studying DC intracellular signalling pathways during the last 8 years to control DC functions.

\section{Constitutive Activation of Intracellular Signalling Pathways to Boost DC Anticancer Activities}

As commented before, the administration of foreign, pathogenic antigens on their own is not sufficient to raise effective immune responses. They need to be presented to $\mathrm{T}$ cells in a context that will lead to their activation and clonal expansion. This is achieved by inflammation driven by several stimuli including pathogen-derived molecules. These pathogen products will bind to receptors recognising pathogen molecular patterns such as toll-like receptors (TLRs) on the surface of DCs. As discussed above, DCs will then mature and present pathogen-derived antigens to specific $\mathrm{T}$ cells. That is exactly the strategy of using adjuvants in vaccination. Adjuvants can be TLR agonists or mediators of inflammation that in combination with the antigens of interest will boost antigen-specific $\mathrm{B}$ and $\mathrm{T}$ cell responses. The classical adjuvant alum was recently found to be a potent inflammasome activator [200, 201]. TLR agonists are being widely used to break immunological tolerance towards autologous TAAs and activate anti-cancer immune responses $[202,203]$. 


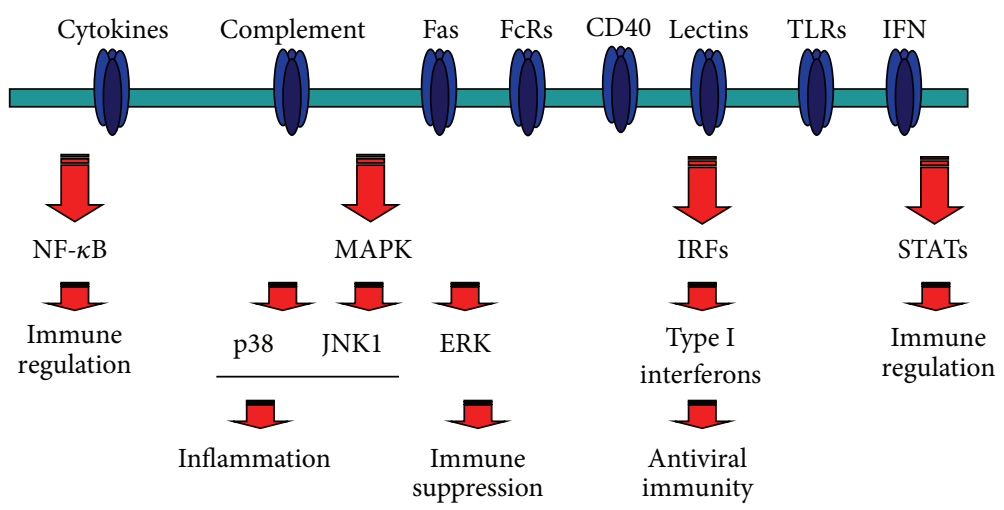

FIGURE 4: Intracellular signalling pathways controlling DC functions. A simplified scheme of the intracellular signalling pathways which control DC maturation and antigen presentation functions is indicated in the figure. On top, the DC plasma membrane containing a series of receptors which will recognise a wide variety of ligands. Some of these receptors are shown on top, such as Fas, immunoglobulin receptors (FcR), CD40, lectin receptors, toll-like receptors (TLR), and interferons (IFN). The binding of the corresponding ligands to their receptors will activate critical signalling pathways, as indicated below the membrane in the figure. Their involvement in several aspects of immune regulation is briefly indicated in the figure below each pathway.

TLR agonists and other adjuvants act by inducing DC maturation. We reasoned that instead of classical adjuvant formulations, we could directly modify DC antigen presenting functions by activating specific signalling pathways by genetic modification. When maturation stimuli as found in adjuvants trigger their corresponding receptors on the surface of DCs, an intricate network of intracellular signalling cascades is initiated. Simplifying, the four key main signalling pathways that activate following TLR and cytokine stimulation are the NF- $\kappa \mathrm{B}$, mitogen-activated protein kinases (MAPKs), interferon-regulatory factors (IRFs), and signal transducer and activator of transcription (STAT) pathways $[12,154,204]$ (Figure 4). These signalling pathways regulate the expression levels of MHC and costimulatory molecules, as well as cytokine production. The administration of adjuvants will stimulate these pathways, but they will also trigger negative feedback mechanisms that will terminate their signalling $[187,205-211]$. These inhibitory mechanisms ensure a control over excessive inflammation that protects the organism against autoreactive disease. However, in cancer immunotherapy, these mechanisms are detrimental for the breaking of immunological tolerance towards TAAs.

To circumvent this problem, we decided to express constitutively active mutants of some of these intracellular signalling pathways. For this purpose, we chose mutants that could be resistant to the activity of negative feedback mechanisms such as MAPK phosphatases. One of the key pathways regulating immunity and inflammation is the NF$\kappa \mathrm{B}$, a transcription factor that translocates to the cell nucleus and transactivates a wide array of inflammation-related genes $[13,212]$. Constitutive NF- $\kappa$ B activation in DCs was achieved by the overexpression of the NF- $\kappa \mathrm{B}$ inducing kinase (NIK) using adenoviral vectors [176]. This approach strongly potentiated the antigen presentation activities of DCs to T cells by triggering their phenotypic maturation and production of proinflammatory cytokines and mediators. NIK-mediated immunostimulatory properties were superior to those of classical adjuvants. However, this strategy was tested using GFP as a model antigen and not for anti-cancer immunotherapy. A similar strategy was applied using lentiviral vectors (lentivectors) by the expression of Kaposi's sarcoma herpesvirus vFLIP protein. vFLIP is a constitutive activator of the NF- $\kappa \mathrm{B}$ pathway, and its activities are associated to cell transformation and oncogenesis [213-215]. Interestingly, its expression in DCs using lentivectors resulted in their phenotypic maturation and production of proinflammatory cytokines, similarly to NIK overexpression using adenoviral vectors [216]. In this case, increase in survival was achieved in an experimental MHC II-negative thymoma model using OVA as a surrogate tumour antigen (EG7 cells) $[178,216]$. Another strategy to achieve sustained NF- $\kappa \mathrm{B}$ activation is to interfere with the negative feedback mechanisms. Recently, the ubiquitin ligase A20 has been found to be a major negative regulator of the NF- $\kappa$ B pathway $[217,218]$. A20 plays a key regulatory role in innate TLR and cytokine dependent immune responses [219-221]. Consequently, siRNA silencing of A20 expression in DCs prolonged NF- $\kappa$ B and AP-1 activation [187]. A20silenced DCs exhibited a higher secretion of IL10, IL6, and IL12. Interestingly, this strategy increased IL10 expression, a potent immunosuppressive cytokine. Therefore, Breckpot and cols simultaneously silenced A20 and IL10 expression, which in turn increased the antigen presenting capacities of human DCs and stimulated the expansion of MART-1specific CD8 $\mathrm{T}$ cells.

TLR stimulation activates the three classes of MAPK pathways: p38, c-jun N-terminal kinases (JNK), and extracellular signal-regulated kinases (ERK). MAPK p38 has been extensively linked in proinflammatory responses and described a key driver of DC phenotypical and functional maturation $[182,222-224]$. Therefore, we tested the effects of its constitutive activation by lentivector expression of an MKK6 mutant [225] that cannot be inactivated by phosphatases. Interestingly, sustained p38 activation in murine bone-marrow-derived DCs (BM-DCs) significantly increased the expression of just a few costimulatory and adhesion molecules (CD80, CD40, and ICAM-I) [134]. To 
our surprise, it did not increase expression of IL12 even though there was at the time experimental evidence using p38 inhibitors that it contributed to IL12 production [12, 224]. However, recent evidence is challenging this view [226], and its contribution might be indirect through NF$\kappa \mathrm{B}$ activation [212] and dependent of the source of DCs [227]. Direct vaccination with a lentivector coexpressing the MKK6 mutant and OVA strongly stimulated the expansion of OVA-specific CD4 and CD8 T cells. Sustained p38 activation in DCs also significantly enhanced CD8 $\mathrm{T}$ cell responses against NY-ESO-1 in a human HLA-A2 transgenic mouse model [134, 228]. MAPK p38-activated human DCs could also support the ex vivo proliferation of MART-1-specific CD8 T cells. Consequently, ex vivo p38-activated OVAexpressing DCs were used as a therapeutic cellular vaccine in the EG7 lymphoma model [134]. Interestingly, an increase in survival was observed although all mice subsequently developed lymphomas due to immunological escape. These results suggested that constitutive p38 activation was not strong enough yet, even though it enhanced the antigen presentation properties of modified DCs. However, tumours always came back even though they were expressing a strongly immunogenic xenoantigen (OVA).

Constitutive JNK1 activation was also tested by DC genetic modification using lentivectors [134]. JNK1 has also been linked to proinflammatory responses and regulation of DC survival $[222,229,230]$. The expression of a fusion protein between MKK7 (JNK upstream kinase) and JNK1 resulted in its constitutive activation and had only a minor effect on DC maturation [134, 231]. Even so, it clearly enhanced CD8 $\mathrm{T}$ cell proliferation after vaccination with a lentivector encoding MKK7-JNK1 and OVA. Nevertheless, this strategy was never tested in a tumour model.

Similarly, the expression of a constitutively active MEK1 mutant using lentivectors resulted in sustained ERK phosphorylation. ERK activation in murine BM-DCs and human monocyte-derived DCs (MoDCs) drove DCs towards a regulatory phenotype, suppressed antigen-specific $\mathrm{T}$ cell expansion, and expanded antigen-specific CD4 Foxp3 Tregs $[134,189]$. Obviously, these DCs could be used to suppress autoimmune disorders such as inflammatory arthritis [189] but could not be used for anti-cancer immunotherapy. Therefore, we constructed a dominant negative MEK1 mutant by replacing the activatory threonine and serine residues by alanines in its activation loop (MEK1 AA). Now the expression of this MEK1 AA mutant in DCs inhibited ERK phosphorylation, which drove DCs to their phenotypical maturation and strongly enhanced their T cell antigen presenting properties [189]. Even so, and following our experience with the MAPK p38, we reasoned that ERK inhibition on its own might not be sufficient to achieve effective anticancer therapeutic activities. Therefore, we combined MEK1 AA expression with delivery of a PD-L1 targeted shRNA in murine DCs and used these genetically modified DCs as a cellular vaccine in an EG7 lymphoma model. PD-L1 is a member of the B7 costimulatory molecules, although it delivers an inhibitory signal to $\mathrm{T}$ cells through binding to PD-1. However, we had observed that PD-L1 silencing in antigen presenting DCs interfered with ligand-induced
TCR downmodulation in CD8 T cells $[148,155]$. This lack of TCR downmodulation hyperactivated $\mathrm{T}$ cells which started to proliferate much earlier and acquire their effector cytotoxic activities shortly after antigen presentation. However, in "physiological" conditions these T cells exponentially expand and down-modulate their TCR, which prevents an untimely attack until a "critical mass" of T cells has been reached [147, 148, 155, 161]. Therefore, just by PD-L1 silencing alone, the expanding $\mathrm{T}$ cells started to attack the tumour much earlier, before reaching their peak of proliferation. The net result was that cancer cells underwent immunoediting early, and the reduced $\mathrm{T}$ cell numbers favoured the selection of escaping T cells. However, with PD-L1 silencing in combination with the ERK inhibitor in DCs, these $\mathrm{T}$ cells could effectively control tumour growth [149]. By using this combination, up to $80 \%$ long-term survival was observed in the EG7 lymphoma mouse model [149]. Interestingly, constitutive activation of p38 together with PD-L1 silencing also achieved similar survival outcomes.

Following this strategy, we launched further experiments using endogenous TAAs instead of OVA. We observed that raising significant TAA-specific $\mathrm{T}$ cell responses using our PD-L1 silencing strategy is harder than what we had expected. As discussed above, there are many discrepancies between the successes observed in experimental cancer models and their corresponding strategies in human clinical practice. These discrepancies are principally due to the activity of potent immunological regulatory mechanisms that ensure immunological tolerance in physiological conditions. These mechanisms are truly immunological barriers for cancer immunotherapy.

\section{Immunological Barriers for Cancer Immunotherapy}

The immune system is capable of recognizing, controlling, and eliminating cancer cells, as they are certainly immunogenic $[37,232]$. However, there are two key barriers for the immune system to overcome to raise effective antitumour responses. The first one is to break the natural immunological tolerance towards self-antigens, which stops the activation of TAA-specific cytotoxic T cells. The second one is tumourinduced immune suppression, which strongly inhibits any immunotherapy treatment used in clinical practice. In fact, this is a main factor contributing to the pathological manifestations of cancer. Patients with advanced cancer possess an immune system so compromised that it is unable to fight infections. These infections complicate their treatment and can quickly lead to their death. So, what causes tumourinduced immune suppression? There are several contributing mechanisms, but it is mainly caused by the expansion of potent immunosuppressive cells. From these, especial mention deserves regulatory $\mathrm{T}$ cells (Tregs) and myeloid-derived suppressor cells (MDSCs).

Thus, the two main goals of cancer immunotherapy are the achievement of strong activation of circulating autoreactive TAA-specific $\mathrm{T}$ cells and to counteract the activity of Tregs and MDSCs. As mentioned earlier in this review, activation of effector TAA-specific $\mathrm{T}$ cells occurs in cancer 


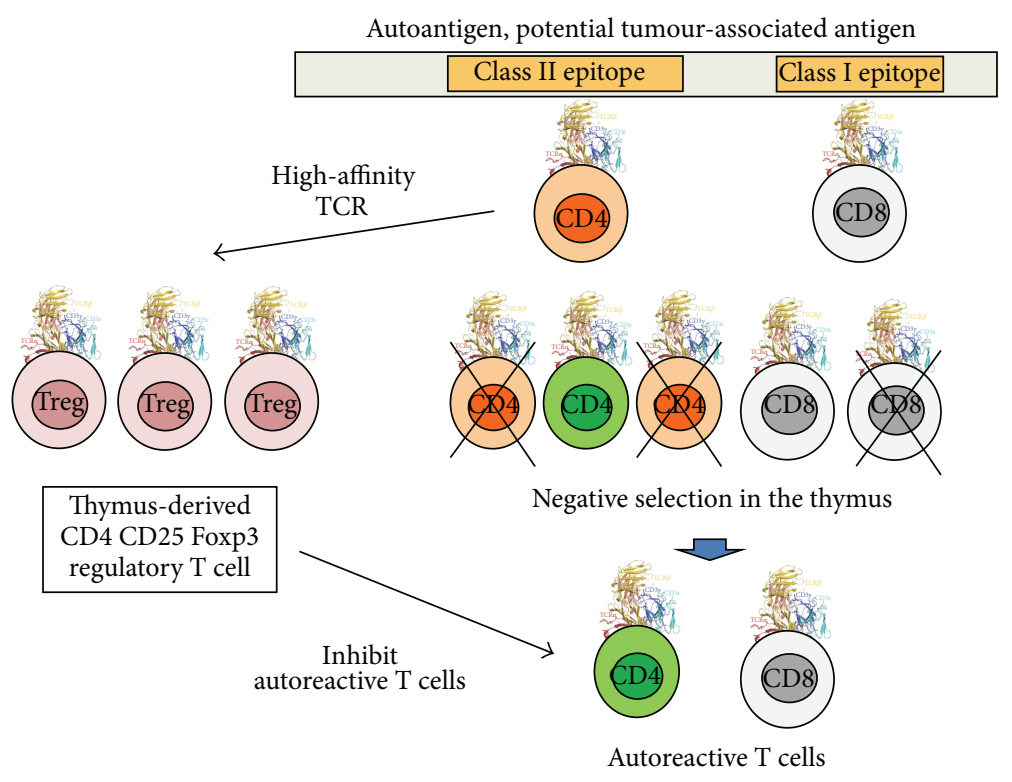

FIGURE 5: Negative selection of autoreactive T cells and natural Treg development. This figure schematically shows a very simplified version of negative selection that takes place in the thymus and removes auto-reactive T cells. On top, a cellular autoantigen expressed in the thymus is shown, containing both class I and class II epitopes as indicated. When developing T cells recognise these peptides, most of them will undergo negative selection as indicated below the represented antigen. These cells will die, and their differentiation will not continue (crossed-out cells). However, a small percentage of low-affinity autoreactive T cells survives negative selection. These can be both CD4 (in green) and CD8 T cells, as shown at the bottom of the figure. However, if CD4 T cells strongly recognise the autoantigen epitope, they can also differentiate into highly suppressive natural Tregs (left on the figure, Treg). When released out of the thymus, these nTregs will control the activity of autoreactive T cells, in case that these get activated "by mistake" during antigen presentation. This is possibly one of the major barriers for cancer immunotherapy, as many of these autoreactive T cells can be potential TAA-specific cytotoxic T cells.

patients, and it can be stimulated by enhancing antigen presentation at the level of DCs. However, the neutralisation of the profound systemic immune suppression in cancer patients with heavy tumour burden remains a challenge. Any immunotherapy treatment, including DC vaccination or the use of strong adjuvants to enhance antigen presentation, has to overcome the strongly immunosuppressive environment in cancer patients. Here lies one of the main factors for the discrepancy between ex vivo preclinical data and in vivo human cancer immunotherapy.

\section{Regulatory T Cells: The "Re-Discovery"}

In physiological conditions, millions of innocuous organisms and compounds are in direct contact with our organism, including bacteria, viruses, all types of "allergens" such as dust mites, pollen and man-made chemicals. During the early-middle 20th century, the medical community including scientists and researchers thought that the immune system was constantly fighting against all these organisms and antigens. Therefore, the immune system was considered a very active sentinel keeping potential threats at bay. This interpretation of immunity has turned out to be not that accurate. It seems that our immune system is kept in a type of "stand-by" state. More precisely, the immune system actively suppresses immune responses, and the net result is systemic tolerance towards most organisms and potential allergens. It would certainly be highly detrimental to raise uncontrolled immune responses towards, let us say, commensal bacteria in our gut. When a truly dangerous threat arises, the immune system is triggered to mount immediate protective responses, leading to medium- and long-term adaptive responses.

However, there was another puzzling property of the immune system. When antipathogen immune reactions take place, no autoimmune reactions appear, apparently. How can our organism differentiate "self" from "non-self"? Obviously, this is a critical question considering cancer immunity, as cancer could be considered as "self." Firstly, systemic central self-tolerance starts during the development of T cells. A high variety of antigen-binding regions are generated when TCRs are assembled, and these also include TCRs that can recognise autoantigens with high, medium, and low affinities. Fortunately, high-affinity autoreactive $\mathrm{T}$ cells are removed in the thymus by a process called clonal deletion [233] (Figure 5). This mechanism eliminates most of the autoreactive $\mathrm{T}$ cells, which certainly helps in the keeping of systemic self-tolerance. However, clonal deletion did not explain autoimmune disorders, a pathological situation in which $\mathrm{B}$ and $\mathrm{T}$ cells recognise certain autologous antigens. These autoreactive cells will attack self-tissues and amplify inflammation leading to the development of diseases such as rheumatoid arthritis, lupus, or ankylosing spondylitis [234]. Therefore, autoreactive $\mathrm{T}$ cells can in fact escape clonal deletion, although in physiological conditions they are 
inactive. The answer to this riddle is that many high-affinity autoreactive $\mathrm{T}$ cells that survive clonal deletion differentiate into natural CD4 Foxp3 Tregs [165, 233] (Figure 5).

8.1. Natural Tregs. Natural Tregs (nTregs) largely contribute to the establishment of central tolerance. These $\mathrm{T}$ cells are intrinsically immunosuppressive and can inhibit the proinflammatory activities of a range of immune cells [165]. Many scientists might believe that Tregs have been recently discovered. It is true that research in Treg biology has exponentially increased relatively recently. However, Tregs are not a new finding by any means. There was ample evidence on their existence in the 1970s. In 1973, suppressor CD4 $\mathrm{T}$ cells originated in the thymus were described [235-237]. However, as the authors mention, they were basically very similar to their immunostimulatory $\mathrm{T}$ helper counterparts and difficult to separate from them [235, 238]. There was even evidence for inducible Tregs [239]. Even more suprisingly, these early studies published experimental designs and conclusions which were nearly identical to the most recent papers on Tregs. For example, there was compelling evidence in the 70s that cyclophosphamide could break immunological tolerance by counteracting $\mathrm{T}$ cell suppressor activities [240]. This observation was "re-discovered" in 2006, 32 years later from the original finding [241]. Even as early as 1974, suppressor cells that could correspond to either Tregs or MDSCs were described in spleens of tumour-bearing mice [242]. The recognition of the existence of MDSCs as a separate immunosuppressive lineage, which accumulate at large numbers in spleens from tumour-bearing mice, was less than 10 years ago [243]. Also in 1974 suppressor T cells were isolated from tolerised mice, and the authors demonstrated their capacities to suppress immune responses in a cell-tocell dependent manner [244]. Similar recent studies are still clarifying these suppressive cell-to-cell mechanisms exerted by Tregs [245-247].

So, if there was so much evidence regarding the existence, how is it possible that all this research was forgotten and "re-discovered" around 2003 [248]? There was a surprising large body of evidence regarding suppressor $\mathrm{T}$ cells, but at the time there were not specific cell markers associated to them. We have to take into account that monoclonal production technology appeared in 1973 [249], and their use for phenotyping of immune cells was not regulated until 1982. Therefore, the phenotypic characterisation of Tregs during the late 70 s and 80 s just simply did not occur. This fact made it difficult to isolate, study, and manipulate them. It was not until the early 2000s when Sakaguchi and colleagues associated high expression levels of CD25 in CD4 T cells with natural Treg activity $[248,250]$. CD25, the high-affinity IL2R chain, has been directly associated to Treg suppressor activities by sequestration of IL2 required for T cell survival and clonal expansion $[251,252]$. In addition, IL2 signalling is required for Treg homeostasis [253].

A major breakthrough took place in 2003 when the Foxp3 transcription factor was shown to be required for Treg development [248]. Other markers and transcription factors have been associated to Tregs [254], but so far only Foxp3 remains the most reliable of them, particularly in mice. The strong association of high levels of CD25 and Foxp3 expression with regulatory $\mathrm{T}$ cells strongly relaunched research on Tregs.

8.2. Inducible Tregs. Nevertheless, nTregs and clonal deletion did not explain the acquired tolerance towards other autoantigens not expressed in the thymus and without mentioning a plethora of foreign antigens to which we constantly come in contact with. Theoretically speaking, immune responses should be constantly in place towards these antigens, although this is not by any means the case. The organism remains tolerant towards most antigens whether they are autoantigens or foreign/xenoantigens. Interestingly, once Foxp3 was described as a Treg marker, another set of Tregs that did not originate directly in the thymus was discovered. These Tregs also coexpressed CD25 and Foxp3 but differentiated in the periphery from naïve and antigenexperienced nonregulatory CD4 T cells [250]. This inducible Foxp3 Tregs (also called Th3 cells) differentiated during antigen presentation by tolerogenic DCs in the absence of inflammation [255]. Negative costimulation and TGF$\beta$ expression mediate inducible Treg differentiation during antigen presentation [189, 256-259]. Another set of inducible CD4+ IL10+ lacking Foxp3 expression cells can also be differentiated by antigen presentation in the presence of IL10, a potent immunosuppressive cytokine [260]. They are known as Trl and also play a key role in maintaining peripheral and mucosal tolerance [261].

8.3. Treg Cells in Cancer. Tregs are major players in keeping systemic immunological tolerance. Unfortunately for cancer immunotherapy, natural Tregs which recognise autoantigens differentiate in the thymus. And even though autoreactive $\mathrm{T}$ cells escape, their activities are controlled by nTregs targeting the same autoantigens. The elimination of Tregs using CD25-depleting antibody results in tumour regression, demonstrating a direct link between the inhibitory activities of Tregs and lack of anti-tumour immune responses [262]. In fact, using a systemic B cell lymphoma model expressing flu haemagglutinin as a surrogate tumour antigens, Zhou and cols demonstrated that tumours induce antigen-specific Tregs [263]. Even after vaccination, both effector antitumour cells and antigen-specific Tregs were expanded, but Tregs could control the antitumour cytotoxic cells. This is a key observation, as it demonstrates that tumours expand Tregs to escape from the $\mathrm{T}$ cell attack. Increased numbers of circulating and tumour-infiltrating Tregs were also observed in cancer patients $[264,265]$. Therefore, even though tumours are certainly immunogenic, TAA-specific $\mathrm{T}$ cells are at the end rendered inactive by Treg activity [266-268]. Thus, Tregs strongly influence the equilibrium between tumour growth and antitumour immune responses towards cancer growth and immune escape.

There is evidence that tumours cause Treg differentiation by converting myeloid DCs into tolerogenic DCs [269]. In addition, tumour cells produce a range of cytokines and metabolic enzymes that stimulate the conversion to Tregs, and some of these also promote MDSC differentiation such as cyclooxygenase and prostaglandin [270]. 
Interestingly, MDSC infiltration in tumours recruits Tregs through chemokine secretion in a CCR5-dependent manner [271]. Therefore, there is a concerted action between MDSCs and Tregs that stimulate tumour progression. Tumours also produce key cytokines and growth factors that can convert Tregs in situ, or in the draining lymph node, such as the prototypical TGF- $\beta$ and IL10.

Tregs inhibit immune responses by a wide range of mechanisms, such as infectious tolerance by amino-acid consumption [272, 273], expression of potent immunosuppressive cytokines such as TGF- $\beta$ and IL10 $[80,260,269]$, and by the delivery of negative signals to antigen presenting cells. Particularly important is this last point, usually mediated by CTLA4 expressed on the surface of Tregs [274]. Even though CTLA4 in Tregs has been extensively studied, the specific mechanisms by which it inhibits immune responses still remain a sort of a mystery [247]. Firstly, as it exhibits a higher affinity for CD80/CD86 than CD28, it has been proposed that CTLA4 competes with CD28 binding CD80/CD86 [275]. This completion would be responsible for the inhibition of APC antigen presentation functions [247, 275]. It could be possible that CTLA4-CD80/CD86 binding would deliver a negative signal to both T cells and APCs. Interestingly, there is strong evidence that Tregs physically remove CD80/CD86 molecules from the surface of antigen presenting cells by transendocytosis [246]. Then, CTLA4-CD80/CD86 complexes would be degraded, leaving APCs without costimulatory molecules. The result would be APCs with highly reduced antigen presenting capacities.

8.4. Tregs as a Target for Cancer Immunotherapy. The therapeutic elimination of Tregs or inhibition of their functions is a major goal for cancer immunotherapy to improve its therapeutic activities [276]. As discussed above, Tregs express CTLA4 and CD25, surface markers that can make them susceptible to antibody-targeted strategies. The combination of a CTLA4 blocking antibody with a CD25depleting antibody in a B16 melanoma model resulted in effective immunotherapy [277]. The elimination of Tregs enhanced immune responses against endogenous TAAs such as TRP2. Likewise, the simultaneous blockade of CTLA4 and PD-1 signalling also strongly inhibits Treg function [278]. Preclinical and clinical data from systemic administration of CTLA4-blocking antibodies clearly show that targeting these immunosuppressive $\mathrm{T}$ cell pathways is an effective therapeutic procedure [279]. The humanised approved antiCTLA4 antibody ipilimumab clearly boosts antitumour activities in human therapy, significantly prolonging survival in melanoma [280-282] and nonsmall cell lung carcinoma patients [283]. Interestingly, it has been demonstrated that the activity of the CTLA4 "blocking" antibody is in fact dependent on the specific Treg depletion within the tumour but not systemically. So, instead of blocking CTLA4 activities on Treg cells, it seems that this antibody physically removes Tregs via macrophages [284]. However, it might not be that effective in less immunogenic cancers [285]. Something to be taken into account is that these antibody-based immunostimulatory strategies exhibit important inflammatory cytotoxicity $[281,282,285]$. Nevertheless, it is likely that better outcomes will be expected in combination therapies [286].

Some DC immunostimulatory treatments can make them resistant to Treg suppressive activity. Genetic modification of DCs using mRNA electroporation expressing a constitutively active TLR4 ligand together with CD40L and CD70 can confer Treg resistance to $\mathrm{T}$ cells and inhibit their suppressive activity towards effector T cells [183]. Likewise, constitutive inhibition of ERK phosphorylation by the expression of the MEK1AA dominant negative mutant or TGF- $\beta$ silencing in antigen presenting DCs can also strongly inhibit the in vivo expansion of inducible Tregs. [189]. Consequently, ERK inhibition synergistically enhanced the antitumour properties of PD-L1 silencing in DCs [149].

Recently, commonly used chemotherapeutic agents such as cyclophosphamide, fluorouracil, and oxaliplatin have been shown to inhibit the development of Tregs ex vivo and in vivo [240, 241]. These effects contribute to their antitumour capacities by stimulating anticancer immune responses. In fact, there is evidence that broad spectrum kinase inhibitors frequently used in chemotherapy have potent immunostimulatory capacities, such as sunitinib [287, 288]. Without them, it is likely that their direct actions against cancer cells [289, 290] would not be sufficient for their full efficacy. Inhibition of tyrosine kinases and MAPK ERK could have strong immunostimulatory activities by stimulating DC maturation and simultaneously inhibiting the expansion of Tregs and MDSCs [12, 288].

\section{Myeloid-Derived Suppressor Cells in Cancer}

While Tregs are certainly important immunosuppressive cells that enhance cancer progression, the central role of another suppressive cell type has come to light in recent years, the myeloid-derived suppressor cell (MDSC).

MDSCs include a heterogeneous myeloid cell population with common phenotypic and functional characteristics, which expand in highly inflammatory environments [291], infection, transplantation, and cancer [292]. In mice, they express high levels of CD11b+ and GR1, a granulocyte-specific marker. GR1 comprises two surface markers, namely, Ly6C and Ly6G, and on the basis of their relative expression, MDSCs are classified into monocytic (Ly6C ${ }^{\text {high }} \mathrm{Ly}_{6} \mathrm{G}^{\text {neg/low }}$ ) and granulocytic (Ly6 $\mathrm{C}^{\text {high }} \mathrm{Ly} 6 \mathrm{G}^{\text {high }}$ ). These murine populations have also their corresponding counterparts in humans [293]. In recent years, MDSCs have been recognised as the cell type largely responsible for tumour-induced immune suppression, causing the inefficacy of immunotherapeutic procedures in clinical practice. These cells have suddenly become a target of interest for researchers, medics, and pharmaceutical companies [294].

In cancer patients with heavy tumour burden, tumours produce cytokines and other molecules that direct myeloid differentiation towards MDSCs instead of monocytes, DCs, macrophages, and inflammatory granulocytes [295-297]. These MDSCs are systemically distributed and infiltrate the tumours where they inhibit antitumour $\mathrm{T}$ cell responses by antigen-specific and unspecific mechanisms [298-300]. 
The spreading of cancer cells from the primary tumour is in itself a key pathological feature of cancer. However, systemic immunosuppression hampers the immune system from eliminating cancer cells. The existence of myeloid cells that contributed to cancer progression has been known for several years. However, only recently MDSCs have been recognised as a specialised lineage of immunosuppressive cells which strongly expand in cancer [301, 302]. Although the recognition of MDSCs as a specific cell lineage has been controversial [243], all experimental evidence strongly supports their existence and role. Tumour-expanded MDSCs possess strong $\mathrm{T}$ cell inhibitory activities by antigen-specific and nonspecific mechanisms [292]. Antigen-specific suppressive mechanisms may include the induction of Tregs due to antigen presentation in the presence of immunosuppressive cytokines or induction of $\mathrm{T}$ cell anergy. $\mathrm{T}$ cell anergy encompasses a two-step process. Firstly, T cells undergo antigen presentation in the absence of significant positive costimulation. That might be the case of MDSCs, which are highly immature myeloid cells. These T cells expand, but with limited, if any, effector activities. Then, after a second antigen encounter such as antigen recognition in target cells, these $\mathrm{T}$ cells become unreactive (anergic). Antigen nonspecific mechanisms include amino-acid depletion by upregulation of amino-acid-consuming enzymes such as arginase- 1 and iNOS expression that would also contribute to arginine depletion. Also, production of immunosuppressive cytokines such as IL10 and TGF- $\beta$ by MDSCs overly inhibits the activity of immune cells [292].

\section{MDSC Differentiation: A Possibility for Therapeutic Targeting?}

MDSCs differentiate in vivo through the activity of a range of cytokines and other cancer cell products. The inflammatory environment also strongly contributes to their differentiation and acquisition of their suppressive activities. Granulocyte monocyte colony stimulating factor (GM-CSF) produced by cancer cells strongly contributes to MDSC differentiation $[296,298,303,304]$, which would explain why the use of GMCSF in human cancer immunotherapy has mixed responses [305-311].

A proinflammatory environment driven either by cytokines or TLR ligands seems to strongly contribute to their differentiation. The combination of GM-CSF with the TLR4 agonist lipopolysaccharide (LPS) drives the differentiation of bone marrow myeloid precursors into MDSC-like cells [296]. These BM-derived MDSCs strongly inhibited T cell responses by a cell-to-cell contact mechanism and iNOS expression, respectively. Cancer cells produce a range of cytokines that not only differentiate MDSCs but also provide them with strong immunosuppressive capacities. The combination of GM-CSF with the proinflammatory cytokine IL6 strongly potentiated their suppressive activities [312, 313]. A range of other cytokines produced by primary tumours and cancer cell lines also contributed to MDSC differentiation although to a minor extent [313]. The presence of IL13 in combination with GM-CSF and M-CSF also results in particularly suppressive
MDSCs [314], and these cells could inhibit experimental graft-versus-host disease through expression of arginase 1.

These observations pose a critical problem for cancer immunotherapy and the possibility of therapeutically targeting MDSC differentiation. A proinflammatory Th1/Th17 type of response is usually thought to be beneficial to activate anticancer cytotoxic cells $[315,316]$. And this might be true to some extent. However, the same proinflammatory environment favours MDSC activation, which in physiological conditions regulates excessive inflammation. Here lies a major problem for an adequate design of cancer immunotherapy protocols. How to raise Th1/Th17 responses without significantly expanding MDSCs and Tregs.

Apart from myeloid-differentiation and proinflammatory cytokines, prostaglandin E2 (PGE2) and TGF- $\beta$ can effectively drive MDSC differentiation, both of them found in abundance in tumour-derived exosomes [317, 318]. PGE2 in combination with GM-CSF, IL4, and LPS differentiates human MDSCs by a positive loop involving COX2 induction [319].

\section{MDSC Targeting for Cancer Immunotherapy}

MDSCs are a tougher therapeutic target in comparison to Tregs. There are Grl-specific depleting antibodies, but in general terms, any myeloid-specific blocking/depleting molecule will possibly eliminate proinflammatory myeloid cells. These cells play a critical role in TAA antigen presentation. As discussed above, there are some chemotherapy drugs and metabolic compounds that inhibit the expansion of MDSCs and Tregs [294], possibly through inhibition of STAT3 signalling. In general terms, both inhibitory T and MDSC cells rely on STAT3 activation for their suppressive activities [288]. In fact, genetic modification of myeloid cells using STAT3targeted silencing shRNA delivered by lentivector vaccination [320].

It is also highly likely that broad spectrum kinase inhibitors already in use in human oncology might shift the balance towards proinflammatory DC differentiation $[12,154]$. However, from a scientific point of view, in preclinical studies, how could these MDSC counteracting drugs be identified without taking them to clinical trials? Currently, MDSCs are isolated directly from spleens or tumours from tumourbearing mice, which renders relatively low numbers. These cell yields are insufficient for large screenings of candidate drugs. Isolated MDSCs fail to proliferate ex vivo, and their survival is severely compromised, which hampers their study and therapeutic applications [321]. Even though they can be differentiated ex vivo from bone marrow or mononuclear cells, the MDSC yields range from $20 \%$ to $40 \%$ in the best cases $[314,319]$. Additionally, there are many differing protocols, which will possibly result in heterogeneous and nonrepresentative MDSC populations. Another key point to take into account is that MDSCs subtly differ depending on the cancer background in which they differentiate [321, 322]. This means that for each type of cancer, large numbers of MDSCs should be reproducibly obtained for large scale, high throughput drug testing. In the meantime, small scale studies 
in mice or from limited human samples have to be performed to study the effects of antineoplastic treatments on MDSC differentiation and functions.

\section{Conclusions}

Does cancer immunotherapy have a "niche" in oncology? According to my opinion, it does. Tumours are certainly immunogenic, and TAA-specific T cells do in fact expand and infiltrate tumours. Even in some infrequent cases there is spontaneous tumour regression. However, a key point in cancer immunotherapy is the development of strong TAAspecific $\mathrm{T}$ cell responses, not only in quality but in quantity to prevent immunological escape as a result of tumour immune editing. One way to achieve this is to potentiate antigen presentation from the beginning, by manipulating the most potent antigen presenting cell, the DCs.

Many biomedical research groups including our own use murine or human ex vivo differentiated DCs to develop anticancer vaccines. These DCs are manipulated to process and present TAA antigen peptides on their MHCs, so that they can be used in antigen presentation assays to $\mathrm{T}$ cells to evaluate the therapeutic potential of a range of antineoplastic treatments. These ex vivo antigen presentation systems and in vivo tumour animal models certainly provide invaluable information to evaluate novel anticancer immunotherapy treatments [149]. However, there are major inconsistent results between preclinical drug testing and clinical trials in human patients. A reason for these discrepancies is that human cancer patients have been suffering the disease for some time. By the time that they go to their physician, tumours have likely exerted their immunosuppressive activities. Therefore, the question is, how can we counteract immunosuppressive cells in their organism?

Treg depletion and inhibition of their differentiation are becoming a reality, even though Treg-depleting treatments are highly toxic. However, new cancer immunotherapy agents have to be aimed at counteracting activity of MDSCs. There is a strong correlation between the success of conventional antineoplastic treatments with inhibition of MDSC and Treg expansion [288, 294, 302].

However, nowadays it is not yet possible to faithfully and efficiently replicate cancer-driven MDSC differentiation ex vivo. If a reproducible and efficient MDSC differentiation system could be set up ex vivo, similar to DC production protocols, antineoplasic treatments could be firstly assessed at preclinical assays. Immortalised MDSC cell lines could be used as substitutes of primary MDSCs [323]. However, these cell lines were obtained by retrovirus transduction to express the oncogenes v-myc and v-raf. It is highly likely that this will alter their behaviour towards antineoplastic treatments.

As a conclusion, tumours are more immunogenic than previously thought. However, the concerted action of several immunosuppressive cells keeps the immune system at bay. Researchers should be looking for a system to test anticancer treatments over Treg and MDSC functions ex vivo. While Tregs can be eliminated using depleting antibodies, MDSCs are more difficult to target. An ex vivo MDSC-T cell antigen presentation assay should conserve MDSC's proliferative capacities and replicate their behaviour as found within tumours [321].

These ex vivo strategies will uncover novel antineoplastic drugs at preclinical assays, which will save the precious economic and human resources required for human clinical trials.

\section{Conflict of Interests}

The author declares no conflict of interests.

\section{Acknowledgments}

The author has been funded by Arthritis Research UK until March 2013, and from then on, by a Miguel Servet Fellowship, Instituto de Salud Carlos III. The author thanks all collaborators and colleagues.

\section{References}

[1] K. V. Holmes and L. Enjuanes, "The SARS coronavirus: a postgenomic era," Science, vol. 300, no. 5624, pp. 1377-1378, 2003.

[2] A. M. Zaki, S. van Boheemen, and T. M. Bestebroer, "Brief report: isolation of a novel coronavirus from a man with pneumonia in Saudi Arabia," The New England Journal of Medicine, vol. 369, article 39, 2013.

[3] "Smallpox eradication: the first three years," WHO Chronicle, vol. 24, no. 7, pp. 301-310, 1970.

[4] C. F. Estivariz, M. A. Pallansch, A. Anand et al., "Poliovirus vaccination options for achieving eradication and securing the endgame," Current Opinion in Virology, vol. 3, no. 3, pp. 309315, 2013.

[5] D. S. Saint-Victor and S. B. Omer, "Vaccine refusal and the endgame: walking the last mile first," Philosophical Transactions of the Royal Society B, vol. 368, no. 1623, Article ID 20120148, 2013.

[6] R. Vivancos, A. Keenan, S. Farmer et al., "An ongoing large outbreak of measles in Merseyside, England," Eurosurveillance, vol. 17, no. 29, 2012.

[7] K. F. Brown, S. J. Long, M. Ramsay et al., "UK parents' decisionmaking about measles-mumps-rubella (MMR) vaccine 10 years after the MMR-autism controversy: a qualitative analysis," Vaccine, vol. 30, no. 10, pp. 1855-1864, 2012.

[8] B. Taylor, E. Miller, C. P. Farrington et al., "Autism and measles, mumps, and rubella vaccine: no epidemiological evidence for a causal association," The Lancet, vol. 353, no. 9169, pp. 2026-2029, 1999.

[9] C. V. Ichim, "Revisiting immunosurveillance and immunostimulation: implications for cancer immunotherapy," Journal of Translational Medicine, vol. 3, article 8, 2005.

[10] F. M. Burnet, "The concept of immunological surveillance," Progress in Experimental Tumor Research, vol. 13, pp. 1-27, 1970.

[11] D. Escors and K. Breckpot, "Lentiviral vectors in gene therapy: their current status and future potential," Archivum Immunologiae et Therapiae Experimentalis, vol. 58, no. 2, pp. 107-119, 2010.

[12] F. Arce, G. Kochan, K. Breckpot, H. Stephenson, and D. Escors, "Selective activation of intracellular signalling pathways in dendritic cells for cancer immunotherapy," Anti-Cancer Agents in Medicinal Chemistry, vol. 12, no. 1, pp. 29-39, 2012. 
[13] K. Breckpot and D. Escors, "Dendritic cells for active anticancer immunotherapy: targeting activation pathways through genetic modification," Endocrine, Metabolic and Immune Disorders, vol. 9, no. 4, pp. 328-343, 2009.

[14] L. Apetoh, F. Ghiringhelli, A. Tesniere et al., "Toll-like receptor 4-dependent contribution of the immune system to anticancer chemotherapy and radiotherapy," Nature Medicine, vol. 13, no. 9, pp. 1050-1059, 2007.

[15] F. Ghiringhelli, L. Apetoh, A. Tesniere et al., "Activation of the NLRP3 inflammasome in dendritic cells induces IL1B-dependent adaptive immunity against tumors," Nature Medicine, vol. 15, no. 10, pp. 1170-1178, 2009.

[16] L. Zitvogel, L. Apetoh, F. Ghiringhelli, and G. Kroemer, "Immunological aspects of cancer chemotherapy," Nature Reviews Immunology, vol. 8, no. 1, pp. 59-73, 2008.

[17] F. Ghiringhelli, M. Bruchard, and L. Apetoh, "Immune effects of 5-fluorouracil: ambivalence matters," Oncoimmunology, vol. 2, no. 3, Article ID e23139, 2013.

[18] H. Bugaut, M. Bruchard, H. Berger et al., "Bleomycin exerts ambivalent antitumor immune effect by triggering both immunogenic cell death and proliferation of regulatory T cells," PLoS ONE, vol. 8, no. 6, Article ID e65181, 2013.

[19] F. Ghiringhelli and L. Apetoh, "Chemotherapy and immunomodulation: from immunogenic chemotherapies to novel therapeutic strategies," Future Oncology, vol. 9, no. 4, pp. 469-472, 2013.

[20] N. Sengupta, T. S. MacFie, T. T. MacDonald, D. Pennington, and A. R. Silver, "Cancer immunoediting and "spontaneous" tumor regression," Pathology Research and Practice, vol. 206, no. 1, pp. $1-8,2010$.

[21] M. Hasek, J. Svoboda, and P. Koldovsky, "Immunological tolerance and the cancer problem," Philippine Journal of Cancer, vol. 33, pp. 535-539, 1963.

[22] J. M. Cruse, W. W. Germany, and A. D. Dulaney, “The demonstration of mouse fibrosarcoma fractions as antigens by latex agglutination reactions," Zeitschrift für Immunitätsforschung und Experimentelle Therapie, vol. 124, pp. 419-427, 1962.

[23] G. Pasternak and A. Graffi, "Induction of resistance against isotransplantation of virus-induced," British Journal of Cancer, vol. 17, pp. 532-539, 1963.

[24] J. P. Glynn, A. R. Blanco, and A. Goldin, "Studies on induced resistance against isotransplants of virus-induced," Cancer Research, vol. 24, pp. 502-508, 1964.

[25] I. Witz, G. Hermann, M. Pikovski, and J. Gross, "The antigenic composition of tumours, sera and urines of tumour-bearing," British Journal of Cancer, vol. 18, pp. 397-406, 1964.

[26] S. Decarvalho, "Preparation of antigens specific of human breast carcinoma by an immunochromatographic method," Nature, vol. 203, no. 4950, pp. 1186-1188, 1964.

[27] H. O. Sjoegren, "Studies on specific transplantation resistance to polyoma-virus-induced tumors. Iv. Stability of the polyoma cell antigen," Journal of the National Cancer Institute, vol. 32, pp. 661-666, 1964.

[28] B. Stueck, L. J. Old, and E. A. Boyse, "Occurrence of soluble antigen in the plasma of mice with virus-induced," Proceedings of the National Academy of Sciences of the United States of, vol. 52, pp. 950-958, 1964.

[29] B. Stück, E. A. Boyse, L. J. Old, and E. A. Carswell, "ML: a new antigen found in leukæmias and mammary tumours of the mouse," Nature, vol. 203, no. 4949, pp. 1033-1034, 1964.
[30] H. S. Rosenkranz, "Viral aetiology of human tumours," Nature, vol. 218, no. 5139, pp. 370-371, 1968.

[31] M. S. Reitz and R. C. Gallo, "Retroviruses of human T cells: their role in the aetiology of adult T-cell leukaemia/lymphoma and the acquired immune deficiency syndrome," Cancer Surveys, vol. 4, no. 2, pp. 313-329, 1985.

[32] G. Klein, “Tumor antigens," Annual Review of Microbiology, vol. 20, pp. 223-252, 1966.

[33] M. J. Casey, G. F. Rabotti, P. S. Sarma, W. T. Lane, H. C. Turner, and R. J. Huebner, "Complement-fixing antigens in hamster tumors induced by the bryan strain of rous sarcoma virus," Science, vol. 151, no. 3714, pp. 1086-1088, 1966.

[34] G. G. Kenter, M. J. P. Welters, A. R. P. M. Valentijn et al., "Vaccination against HPV-16 oncoproteins for vulvar intraepithelial neoplasia," The New England Journal of Medicine, vol. 361, no. 19, pp. 1838-1847, 2009.

[35] G. Haughton and D. B. Amos, "Immunology of carcinogenesis," Cancer Research, vol. 28, no. 9, pp. 1839-1840, 1968.

[36] H. J. Smith, "Antigenicity of carcinogen-induced and spontaneous tumours in inbred mice," British Journal of Cancer, vol. 20, no. 4, pp. 831-837, 1966.

[37] T. Tran, D. Burt, L. Eapen, and O. R. Keller, "Spontaneous regression of metastatic melanoma after inoculation with tetanus-diphtheria-pertussis vaccine," Current Oncology, vol. 20, no. 3, pp. e270-e273, 2013.

[38] F. W. Stewart, "Experiences in spontaneous regression of neoplastic disease in man," Texas Reports on Biology and Medicine, vol. 10, no. 1, pp. 239-253, 1952.

[39] R. Dalla Favera, E. P. Gelmann, and S. Martinotti, "Cloning and characterization of different human sequences related to the onc gene (v-myc) of avian myelocytomatosis virus (MC29)," Proceedings of the National Academy of Sciences of the United States of America, vol. 79, no. 21, pp. 6497-6501, 1982.

[40] S. P. Goff, P. D'Eustachio, F. H. Ruddle, and D. Baltimore, "Chromosomal assignment of the endogenous proto-oncogene C-abl," Science, vol. 218, no. 4579, pp. 1317-1319, 1982.

[41] L. F. Parada, C. J. Tabin, C. Shih, and R. A. Weinberg, "Human EJ bladder carcinoma oncogene is homologue of Harvey sarcoma virus ras gene," Nature, vol. 297, no. 5866, pp. 474-478, 1982.

[42] B. Vennstrom, "Isolation and characterization of chicken DNA homologous to the two putative oncogenes of avian erythroblastosis virus," Cell, vol. 28, no. 1, pp. 135-143, 1982.

[43] B. Vennstrom, D. Sheiness, J. Zabielski, and J. M. Bishop, "Isolation and characterization of c-myc, a cellular homolog of the oncogene (v-myc) of avian myelocytomatosis virus strain 29," Journal of Virology, vol. 42, no. 3, pp. 773-779, 1982.

[44] I. S. Y. Chen, K. C. Wilhelmsen, and H. M. Temin, "Structure and expression of c-rel, the cellular homolog to the oncogene of reticuloendotheliosis virus strain T," Journal of Virology, vol. 45, no. 1, pp. 104-113, 1983.

[45] K. H. Klempnauer, G. Ramsay, and J. M. Bishop, "The product of the retroviral transforming gene $\mathrm{v}$-myb is a truncated version of the protein encoded by the cellular oncogene c-myb," Cell, vol. 33, no. 2, pp. 345-355, 1983.

[46] U. R. Rapp, M. D. Goldsborough, and G. E. Mark, "Structure and biological activity of v-raf, a unique oncogene transduced by a retrovirus," Proceedings of the National Academy of Sciences of the United States of America, vol. 80, no. 14, pp. 4218-4222, 1983.

[47] E. Santos, D. Martin Zanca, and E. P. Reddy, "Malignant activation of a K-ras oncogene in lung carcinoma but not in 
normal tissue of the same patient," Science, vol. 223, no. 4637, pp. 661-664, 1984.

[48] M. Barbacid, "Oncogenes and human cancer: cause or consequence?” Carcinogenesis, vol. 7, no. 7, pp. 1037-1042, 1986.

[49] M. Malumbres and M. Barbacid, "Cell cycle kinases in cancer," Current Opinion in Genetics and Development, vol. 17, no. 1, pp. 60-65, 2007.

[50] R. Iggo, K. Gatter, J. Bartek, D. Lane, and A. L. Harris, "Increased expression of mutant forms of $\mathrm{p} 53$ oncogene in primary lung cancer," The Lancet, vol. 335, no. 8691, pp. 675-679, 1990.

[51] D. J. Slamon, T. C. Boone, and R. C. Seeger, "Identification and characterization of the protein encoded by the human $\mathrm{N}$-myc oncogene," Science, vol. 232, no. 4751, pp. 768-772, 1986.

[52] W.-H. Lee, J.-Y. Shew, F. D. Hong et al., “The retinoblastoma susceptibility gene encodes a nuclear phosphoprotein associated with DNA binding activity," Nature, vol. 329, no. 6140, pp. 642645, 1987.

[53] M. A. Cheever, J. P. Allison, A. S. Ferris et al., "The prioritization of cancer antigens: a National Cancer Institute pilot project for the acceleration of translational research," Clinical Cancer Research, vol. 15, no. 17, pp. 5323-5337, 2009.

[54] T. B. Fitzpatrick, A. B. Lerner, E. Calkins, and W. H. Summerson, "Occurrence of tyrosinase in horse and fish melanomas," Proceedings of the Society for Experimental Biology and Medicine, vol. 75, no. 2, pp. 394-398, 1950.

[55] T. B. Fitzpatric, "Human melanogenesis; the tyrosinase reaction in pigment cell neoplasms, with particular reference to the malignant melanoma; preliminary report," A. M. A. Archives of Dermatology and Syphilology, vol. 65, no. 4, pp. 379-391, 1952.

[56] T. L. Darrow, C. L. Slingluff Jr., and H. F. Seigler, "The role of HLA class I antigens in recognition of melanoma cells by tumorspecific cytotoxic T lymphocytes. Evidence for shared tumor antigens," Journal of Immunology, vol. 142, no. 9, pp. 3329-3335, 1989.

[57] V. Brichard, A. Van Pel, T. Wolfel et al., "The tyrosinase gene codes for an antigen recognized by autologous cytolytic $\mathrm{T}$ lymphocytes on HLA-A2 melanomas," Journal of Experimental Medicine, vol. 178, no. 2, pp. 489-495, 1993.

[58] S. L. Topalian, L. Rivoltini, M. Mancini et al., "Human CD4 ${ }^{+}$ $\mathrm{T}$ cells specifically recognize a shared melanoma-associated antigen encoded by the tyrosinase gene," Proceedings of the National Academy of Sciences of the United States of America, vol. 91, no. 20, pp. 9461-9465, 1994.

[59] A. A. Tarhini, S. Leng, S. J. Moschos et al., "Safety and immunogenicity of vaccination with MART-1 (26-35, 27L), gp100 (209$217,210 \mathrm{M})$, and tyrosinase $(368-376,370 \mathrm{D})$ in adjuvant with PF-3512676 and GM-CSF in metastatic melanoma," Journal of Immunotherapy, vol. 35, no. 4, pp. 359-366, 2012.

[60] A. Ribas, J. S. Weber, B. Chmielowski et al., "Intra-lymph node prime-boost vaccination against Melan A and tyrosinase for the treatment of metastatic melanoma: results of a phase 1 clinical trial," Clinical Cancer Research, vol. 17, no. 9, pp. 2987-2996, 2011.

[61] P. Gold and S. O. Freedman, "Demonstration of tumor-specific antigens in human colonic carcinomata by immunological tolerance and absorption techniques," The Journal of Experimental Medicine, vol. 121, pp. 439-462, 1965.

[62] P. Gold, M. Gold, and S. O. Freedman, "Cellular location of carcinoembryonic antigens of the human digestive system," Cancer Research, vol. 28, no. 7, pp. 1331-1334, 1968.

[63] A. H. Rule and M. E. Kirch, "Gene activation of molecules with carcinoembryonic antigen determinants in fetal development and in adenocarcinoma of the colon," Cancer Research, vol. 36, no. 9, pp. 3503-3509, 1976.

[64] S. A. Halter, L. D. Fraker, M. Parmenter, and W. D. Dupont, "Carcinoembryonic antigen expression and patient survival in carcinoma of the breast," Oncology, vol. 41, no. 5, pp. 297-302, 1984.

[65] W. Savino, D. Durand, and M. Dardenne, "Immunohistochemical evidence for the expression of the carcinoembryonic antigen by human thymic epithelial cells in vitro and in neoplastic conditions," American Journal of Pathology, vol. 121, no. 3, pp. 418-425, 1985.

[66] W. H. Allum, H. J. Stokes, F. MacDonald, and J. W. L. Fielding, "Demonstration of carcinoembryonic antigen (CEA) expression in normal, chronically inflamed, and malignant pancreatic tissue by immunohistochemistry," Journal of Clinical Pathology, vol. 39, no. 6, pp. 610-614, 1986.

[67] J. Kim, F. J. Kaye, J. G. Henslee et al., "Expression of carcinoembryonic antigen and related genes in lung and gastrointestinal cancers," International Journal of Cancer, vol. 52, no. 5, pp. 718$725,1992$.

[68] K. Y. Tsang, S. Zaremba, C. A. Nieroda, M. Z. Zhu, J. M. Hamilton, and J. Schlom, "Generation of human cytotoxic T cells specific for human carcinoembryonic antigen epitopes from patients immunized with recombinant vaccinia-CEA vaccine," Journal of the National Cancer Institute, vol. 87, no. 13, pp. 982-990, 1995.

[69] A. J. A. Bremers, S. H. Van der Burg, P. J. K. Kuppen, W. M. Kast, C. J. H. Van de Velde, and C. J. M. Melief, "The use of Epstein-Barr virus-transformed B lymphocyte cell lines in a peptide-reconstitution assay: identification of CEA-related HLA-A*0301- restricted potential cytotoxic T-lymphocyte epitopes," Journal of Immunotherapy, vol. 18, no. 2, pp. 77-85, 1995.

[70] I. Kawashima, V. Tsai, S. Southwood, K. Takesako, A. Sette, and E. Celis, "Identification of HLA-A3-restricted cytotoxic T lymphocyte epitopes from carcinoembryonic antigen and HER$2 /$ neu by primary in vitro immunization with peptide-pulsed dendritic cells," Cancer Research, vol. 59, no. 2, pp. 431-435, 1999.

[71] I. Nukaya, M. Yasumoto, T. Iwasaki et al., "Identification of HLA-A24 epitope peptides of carcinoembryonic antigen which induce tumor-reactive cytotoxic T lymphocyte," International Journal of Cancer, vol. 80, no. 1, pp. 92-97, 1999.

[72] E. Huarte, P. Sarobe, J. J. Lasarte et al., "Identification of HLAB27-restricted cytotoxic T lymphocyte epitope from carcinoembryonic antigen," International Journal of Cancer, vol. 97, no. 1, pp. 58-63, 2002.

[73] J. Schmitz, E. Reali, J. W. Hodge et al., "Identification of an interferon- $\gamma$-inducible carcinoembryonic antigen (CEA) $\mathrm{CD}^{+}$ T-cell epitope, which mediates tumor killing in CEA transgenic mice," Cancer Research, vol. 62, no. 17, pp. 5058-5064, 2002.

[74] G. J. Ullenhag, J. Fagerberg, K. Strigård, J.-E. Frödin, and H. Mellstedt, "Functional HLA-DR T cell epitopes of CEA identified in patients with colorectal carcinoma immunized with the recombinant protein CEA," Cancer Immunology, Immunotherapy, vol. 53, no. 4, pp. 331-337, 2004.

[75] G. Campi, M. Crosti, G. Consogno et al., "CD4 ${ }^{+} \mathrm{T}$ cells from healthy subjects and colon cancer patients recognize a carcinoembryonic antigen-specific immunodominant Epitope," Cancer Research, vol. 63, no. 23, pp. 8481-8486, 2003.

[76] S. R. Gameiro, M. L. Jammeh, and J. W. Hodge, "Cancer vaccines targeting carcinoembryonic antigen: state-of-the-art and future promise," Expert Review of Vaccines, vol. 12, no. 6, pp. 617-629, 2013. 
[77] C. Merrin, E. Sarcione, M. Bohne, and D. J. Albert, "Alphafetoprotein in testicular tumors," Journal of Surgical Research, vol. 15, no. 4, pp. 309-312, 1973.

[78] J. Houštěk, J. Masopust, K. Kithier, and J. Rádl, “Hepatocellular carcinoma in association with a specific fetal $\alpha 1$-globulin, fetoprotein," The Journal of Pediatrics, vol. 72, no. 2, pp. 186-193, 1968.

[79] C. Li, Z. Zhang, P. Zhang, and J. Liu, "Diagnostic accuracy of des-gamma-carboxy prothrombin versus alpha-fetoprotein for hepatocellular carcinoma: a systematic review," Hepatology Research, 2013.

[80] A. Alisa, S. Boswell, A. A. Pathan, L. Ayaru, R. Williams, and S. Behboudi, "Human CD $4^{+} \mathrm{T}$ cells recognize an epitope within $\alpha$ fetoprotein sequence and develop into TGF- $\beta$-producing CD $4^{+}$ T cells," Journal of Immunology, vol. 180, no. 7, pp. 5109-5117, 2008.

[81] L. H. Butterfield, A. Koh, W. Meng et al., "Generation of human T-cell responses to an HLA-A2.1-restricted peptide epitope derived from $\alpha$-fetoprotein," Cancer Research, vol. 59, no. 13, pp. 3134-3142, 1999.

[82] L. H. Butterfield, W. S. Meng, A. Koh et al., "T cell responses to HLA-A ${ }^{*}$ 0201-restricted peptides derived from human $\alpha$ fetoprotein," Journal of Immunology, vol. 166, no. 8, pp. 53005308, 2001.

[83] W. S. Meng, L. H. Butterfield, A. Ribas et al., "Fine specificity analysis of an HLA-A2.1-restricted immunodominant $\mathrm{T}$ cell epitope derived from human $\alpha$-fetoprotein," Molecular Immunology, vol. 37, no. 16, pp. 943-950, 2001.

[84] R. Thimme, M. Neagu, T. Boettler et al., "Comprehensive analysis of the $\alpha$-fetoprotein-specific $\mathrm{CD}^{+} \mathrm{T}$ cell responses in patients with hepatocellular carcinoma," Hepatology, vol. 48, no. 6, pp. 1821-1833, 2008.

[85] E. Mizukoshi, Y. Nakamoto, H. Tsuji, T. Yamashita, and S. Kaneko, "Identification of $\alpha$-fetoprotein-derived peptides recognized by cytotoxic T lymphocytes in HLA-A24+ patients with hepatocellular carcinoma," International Journal of Cancer, vol. 118, no. 5, pp. 1194-1204, 2006.

[86] L. H. Butterfield, A. Ribas, W. S. Meng et al., "T-cell responses to HLA-A $* 0201$ immunodominant peptides derived from $\alpha$ fetoprotein in patients with hepatocellular cancer," Clinical Cancer Research, vol. 9, no. 16, pp. 5902-5908, 2003.

[87] F. Tada, M. Abe, M. Hirooka et al., "Phase I/II study of immunotherapy using tumor antigen-pulsed dendritic cells in patients with hepatocellular carcinoma," International Journal of Oncology, vol. 41, no. 5, pp. 1601-1609, 2012.

[88] R. C. Bast Jr., M. Feeney, and H. Lazarus, "Reactivity of a monoclonal antibody with human ovarian carcinoma," Journal of Clinical Investigation, vol. 68, no. 5, pp. 1331-1337, 1981.

[89] R. C. Bast Jr., T. L. Klug, and E. St. John, "A radioimmunoassay using a monoclonal antibody to monitor the course of epithelial ovarian cancer," The New England Journal of Medicine, vol. 309, no. 15 , pp. 883-887, 1983.

[90] A. A. Noujaim, B. C. Schultes, R. P. Baum, and R. Madiyalakan, "Induction of CA125-specific B and T cell responses in patients injected with MAb-B43.13-evidence for antibody-mediated antigen-processing and presentation of CA125 in vivo," Cancer Biotherapy and Radiopharmaceuticals, vol. 16, no. 3, pp. 187-203, 2001.

[91] A. N. Gordon, B. C. Schultes, H. Gallion et al., "CA125- and tumor-specific T-cell responses correlate with prolonged survival in oregovomab-treated recurrent ovarian cancer patients," Gynecologic Oncology, vol. 94, no. 2, pp. 340-351, 2004.
[92] S. Bellone, S. Anfossi, T. J. O’Brien et al., “Generation of CA125specific cytotoxic T lymphocytes in human leukocyte antigenA2.1-positive healthy donors and patients with advanced ovarian cancer," American Journal of Obstetrics and Gynecology, vol. 200, no. 1, pp. 75.e1-75.e10, 2009.

[93] T. A. Stamey, N. Yang, and A. R. Hay, "Prostate-specific antigen as a serum marker for adenocarcinoma of the prostate," The New England Journal of Medicine, vol. 317, no. 15, pp. 909-916, 1987.

[94] B. Seamonds, B. Whitaker, and N. Yang, "Evaluation of prostatespecific antigen and prostatic acid phosphatase as prostate cancer markers," Urology, vol. 28, no. 6, pp. 472-479, 1986.

[95] J. W. Hodge, J. Schlom, S. J. Donohue et al., "A recombinant vaccinia virus expressing human prostate-specific antigen (PSA): safety and immunogenicity in a non-human primate," International Journal of Cancer, vol. 63, no. 2, pp. 231-237, 1995.

[96] N. Meidenbauer, D. T. Harris, L. E. Spitler, and T. L. Whiteside, "Generation of PSA-reactive effector cells after vaccination with a PSA-based vaccine in patients with prostate cancer," Prostate, vol. 43, no. 2, pp. 88-100, 2000.

[97] S. Perambakam, S. Hallmeyer, S. Reddy et al., "Induction of specific $\mathrm{T}$ cell immunity in patients with prostate cancer by vaccination with PSA146-154 peptide," Cancer Immunology, Immunotherapy, vol. 55, no. 9, pp. 1033-1042, 2006.

[98] P. Correale, K. Walmsley, C. Nieroda et al., "In vitro generation of human cytotoxic T lymphocytes specific for peptides derived from prostate-specific antigen," Journal of the National Cancer Institute, vol. 89, no. 4, pp. 293-300, 1997.

[99] P. Correale, K. Walmsley, S. Zaremba, M. Zhu, J. Schlom, and K. Y. Tsang, "Generation of human cytolytic T lymphocyte lines directed against prostate-specific antigen (PSA) employing a PSA oligoepitope peptide," Journal of Immunology, vol. 161, no. 6, pp. 3186-3194, 1998.

[100] J. M. Corman, E. E. Sercarz, and N. K. Nanda, "Recognition of prostate-specific antigenic peptide determinants by human CD4 and CD8 T cells," Clinical and Experimental Immunology, vol. 114, no. 2, pp. 166-172, 1998.

[101] M. Harada, K. Kobayashi, S. Matsueda, M. Nakagawa, M. Noguchi, and K. Itoh, "Prostate-specific antigen-derived epitopes capable of inducing cellular and humoral responses in HLA-A24+ prostate cancer patients," Prostate, vol. 57, no. 2, pp. 152-159, 2003.

[102] H. S. Lee, S. W. Kim, J. C. Hong et al., "Expression of MAGE A1-6 and the clinical characteristics of papillary thyroid carcinoma," Anticancer Research, vol. 33, no. 4, pp. 1731-1735, 2013.

[103] D. W. Meek and L. Marcar, "MAGE-A antigens as targets in tumour therapy," Cancer Letters, vol. 324, no. 2, pp. 126-132, 2012.

[104] E. De Plaen, K. Arden, C. Traversari et al., "Structure, chromosomal localization, and expression of 12 genes of the MAGE family," Immunogenetics, vol. 40, no. 5, pp. 360-369, 1994.

[105] P. Van Der Bruggen, C. Traversari, P. Chomez et al., "A gene encoding an antigen recognized by cytolytic $\mathrm{T}$ lymphocytes on a human melanoma," Science, vol. 254, no. 5038, pp. 1643-1647, 1991.

[106] C. Traversari, P. Van der Bruggen, I. F. Luescher et al., "A nonapeptide encoded by human gene MAGE-1 is recognized on HLA-A1 by cytolytic T lymphocytes directed against tumor antigen MZ2-E," Journal of Experimental Medicine, vol. 176, no. 5, pp. 1453-1457, 1992.

[107] F. Brasseur, M. Marchand, R. Vanwijck et al., "Human gene MAGE-1, which codes for a tumor-rejection antigen, is 
expressed by some breast tumors," International Journal of Cancer, vol. 52, no. 5, pp. 839-841, 1992.

[108] P. Chaux, R. Luiten, N. Demotte et al., "Identification of five MAGE-A1 epitopes recognized by cytolytic T lymphocytes obtained by in vitro stimulation with dendritic cells transduced with MAGE-A1," Journal of Immunology, vol. 163, no. 5, pp. 2928-2936, 1999.

[109] P. Chaux, V. Vantomme, V. Stroobant et al., "Identification of MAGE-3 epitopes presented by HLA-DR molecules to CD4 ${ }^{+} \mathrm{T}$ lymphocytes," Journal of Experimental Medicine, vol. 189, no. 5, pp. 767-778, 1999.

[110] M. T. Duffour, P. Chaux, C. Lurquin, G. Cornelis, T. Boon, and P. van der Bruggen, "MAGE-A4 peptide presented by HLA-A2 is recognized by cytolytic T lymphocytes," European Journal of Immunology, vol. 29, no. 10, pp. 3329-3337, 1999.

[111] C. Germeau, W. Ma, F. Schiavetti et al., "High frequency of antitumor $\mathrm{T}$ cells in the blood of melanoma patients before and after vaccination with tumor antigens," Journal of Experimental Medicine, vol. 201, no. 2, pp. 241-248, 2005.

[112] T. Cohan, R. M. Muller, Y. Tomita, and S. Shibahara, "Nucleotide sequence of the cDNA encoding human tyrosinaserelated protein," Nucleic Acids Research, vol. 18, no. 9, pp. 28072808, 1990.

[113] I. J. Jackson, D. M. Chambers, K. Tsukamoto et al., "A second tyrosinase-related protein, TRP-2, maps to and is mutated at the mouse slaty locus," EMBO Journal, vol. 11, no. 2, pp. 527-535, 1992.

[114] R.-F. Wang, E. Appella, Y. Kawakami, X. Kang, and S. A. Rosenberg, "Identification of TRP-2 as a human tumor antigen recognized by cytotoxic T lymphocytes," Journal of Experimental Medicine, vol. 184, no. 6, pp. 2207-2216, 1996.

[115] R.-F. Wang, S. L. Johnston, S. Southwood, A. Sette, and S. A. Rosenberg, "Recognition of an antigenic peptide derived from tyrosinase-related protein- 2 by CTL in the context of HLA-A31 and -A33," Journal of Immunology, vol. 160, no. 2, pp. 890-897, 1998.

[116] M. R. Parkhurst, E. B. Fitzgerald, S. Southwood, A. Sette, S. A. Rosenberg, and Y. Kawakami, "Identification of a shared HLA$\mathrm{A}^{*}$ 0201-restricted T-cell epitope from the melanoma antigen tyrosinase-related protein 2 (TRP2)," Cancer Research, vol. 58, no. 21, pp. 4895-4901, 1998.

[117] C. Castelli, P. Tarsini, A. Mazzocchi et al., "Novel HLACw8-restricted $\mathrm{T}$ cell epitopes derived from tyrosinase-related protein-2 and gp100 melanoma antigens," Journal of Immunology, vol. 162, no. 3, pp. 1739-1748, 1999.

[118] C. Noppen, F. Levy, L. Burri et al., "Naturally processed and concealed HLA-A2. 1-restricted epitopes from tumor-associated antigen tyrosinase-related protein-2," International Journal of Cancer, vol. 87, no. 2, pp. 241-246, 2000.

[119] Y. Sun, M. Song, S. Stevanovic et al., "Identification of a new HLA-A $\left({ }^{*}\right)$ 0201-restricted T-cell epitope from the tyrosinaserelated protein 2 (TRP2) melanoma antigen," International Journal of Cancer, vol. 87, no. 3, pp. 399-404, 2000.

[120] Y. Liu, Y. Peng, M. Mi et al., "Lentivector immunization stimulates potent CD8 $\mathrm{T}$ cell responses against melanoma selfantigen tyrosinase-related protein 1 and generates antitumor immunity in mice," Journal of Immunology, vol. 182, no. 10, pp. 5960-5969, 2009.

[121] W. Osen, S. Soltek, M. Song et al., "Screening of human tumor antigens for $\mathrm{CD}^{+} \mathrm{T}$ cell epitopes by combination of HLAtransgenic mice, recombinant adenovirus and antigen peptide libraries," PLoS ONE, vol. 5, no. 11, Article ID e14137, 2010.
[122] S. R. Sierro, A. Donda, R. Perret et al., "Combination of lentivector immunization and low-dose chemotherapy or PD1/PD-L1 blocking primes self-reactive T cells and induces antitumor immunity," European Journal of Immunology, vol. 41, no. 8, pp. 2217-2228, 2011.

[123] W. W. Overwijk, D. S. Lee, D. R. Surman et al., "Vaccination with a recombinant vaccinia virus encoding a "self" antigen induces autoimmune vitiligo and tumor cell destruction in mice: requirement for $\mathrm{CD} 4^{+} \mathrm{T}$ lymphocytes," Proceedings of the National Academy of Sciences of the United States of America, vol. 96, no. 6, pp. 2982-2987, 1999.

[124] H. T. Khong and S. A. Rosenberg, "Pre-existing immunity to tyrosinase-related protein (TRP)-2, a new TRP-2 isoform, and the NY-ESO-1 melanoma antigen in a patient with a dramatic response to immunotherapy," Journal of Immunology, vol. 168, no. 2, pp. 951-956, 2002.

[125] V. Bronte, E. Apolloni, R. Ronca et al., "Genetic vaccination with 'self' tyrosinase-related protein 2 causes melanoma eradication but not vitiligo," Cancer Research, vol. 60, no. 2, pp. 253-258, 2000.

[126] C. Vennegoor, H. P. Hageman Ph., H. Van Nouhuijs et al., "A monoclonal antibody specific for cells of the melanocyte lineage," American Journal of Pathology, vol. 130, no. 1, pp. 179192,1988

[127] A. B. H. Bakker, M. W. J. Schreurs, A. J. De Boer et al., "Melanocyte lineage-specific antigen gp100 is recognized by melanoma-derived tumor-infiltrating lymphocytes," Journal of Experimental Medicine, vol. 179, no. 3, pp. 1005-1009, 1994.

[128] G. J. Adema, A. J. De Boer, A. M. Vogel, W. A. M. Loenen, and C. G. Figdor, "Molecular characterization of the melanocyte lineage-specific antigen gp100," Journal of Biological Chemistry, vol. 269, no. 31, pp. 20126-20133, 1994.

[129] Y.-T. Chen, A. D. Boyer, C. S. Viars, S. Tsang, L. J. Old, and K. C. Arden, "Genomic cloning and localization of CTAG, a gene encoding an autoimmunogenic cancer-testis antigen NY-ESO1, to human chromosome Xq28," Cytogenetics and Cell Genetics, vol. 79, no. 3-4, pp. 237-240, 1997.

[130] Y.-T. Chen, M. J. Scanlan, U. Sahin et al., "A testicular antigen aberrantly expressed in human cancers detected by autologous antibody screening," Proceedings of the National Academy of Sciences of the United States of America, vol. 94, no. 5, pp. 19141918, 1997.

[131] S. Eikawa, K. Kakimi, M. Isobe et al., "Induction of CD8 T-cell responses restricted to multiple HLA class I alleles in a cancer patient by immunization with a 20-mer NY-ESO-1f (NY-ESO-1 91-110) peptide," International Journal of Cancer, vol. 132, no. 2, pp. 345-354, 2013.

[132] Y. Mizote, T. Taniguchi, K. Tanaka et al., "Three novel NYESO-1 epitopes bound to DRB10803, DQB10401 and DRB1 0901 recognized by CD4 T cells from CHP-NY-ESO-1-vaccinated patients," Vaccine, vol. 28, no. 32, pp. 5338-5346, 2010.

[133] N. C. Robson, T. McAlpine, A. J. Knights et al., "Processing and cross-presentation of individual HLA-A, -B, or -C epitopes from NY-ESO-1 or an HLA-A epitope for Melan-A differ according to the mode of antigen delivery," Blood, vol. 116, no. 2, pp. 218-225, 2010.

[134] D. Escors, L. Lopes, R. Lin et al., "Targeting dendritic cell signaling to regulate the response to immunization," Blood, vol. 111, no. 6, pp. 3050-3061, 2008.

[135] E. Jäger, D. Jäger, J. Karbach et al., "Identification of NYESO-1 epitopes presented by human histocompatibility antigen 
(HLA)-DRB4 $\left({ }^{*}\right)$ 0101-0103 and recognized by CD4 ${ }^{+}$T lymphocytes of patients with NY-ESO-1-expressing melanoma," Journal of Experimental Medicine, vol. 191, no. 4, pp. 625-630, 2000.

[136] K. Odunsi, J. Matsuzaki, J. Karbach et al., "Efficacy of vaccination with recombinant vaccinia and fowlpox vectors expressing NY-ESO-1 antigen in ovarian cancer and melanoma patients," Proceedings of the National Academy of Sciences of the United States of America, vol. 109, no. 15, pp. 5797-5802, 2012.

[137] S. Gnjatic, H. Nishikawa, A. A. Jungbluth et al., "NY-ESO-1: review of an immunogenic tumor antigen," Advances in Cancer Research, vol. 95, pp. 1-30, 2006.

[138] J. Campos-Perez, J. Rice, D. Escors et al., "DNA fusion vaccine designs to induce tumor-lytic $\mathrm{CD}^{+} \mathrm{T}$-cell attack via the immunodominant cysteine-containing epitope of NY-ESO 1," International Journal of Cancer, vol. 133, no. 6, pp. 1400-1407, 2013.

[139] P. F. Robbins, R. A. Morgan, S. A. Feldman et al., "Tumor regression in patients with metastatic synovial cell sarcoma and melanoma using genetically engineered lymphocytes reactive with NY-ESO-1," Journal of Clinical Oncology, vol. 29, no. 7, pp. 917-924, 2011.

[140] Y. Kawakami, S. Eliyahu, C. H. Delgado et al., "Identification of a human melanoma antigen recognized by tumor-infiltrating lymphocytes associated with in vivo tumor rejection," Proceedings of the National Academy of Sciences of the United States of America, vol. 91, no. 14, pp. 6458-6462, 1994.

[141] Y. Kawakami, S. Eliyahu, K. Sakaguchi et al., "Identification of the immunodominant peptides of the MART-1 human melanoma antigen recognized by the majority of HLA-A2restricted tumor infiltrating lymphocytes," Journal of Experimental Medicine, vol. 180, no. 1, pp. 347-352, 1994.

[142] K. S. Lang, C. C. Caroli, A. Muhm et al., "HLA-A2 restricted, melanocyte-specific $\mathrm{CD}^{+} \mathrm{T}$ lymphocytes detected in vitiligo patients are related to disease activity and are predominantly directed against MelanA/MART1," Journal of Investigative Dermatology, vol. 116, no. 6, pp. 891-897, 2001.

[143] S. Bobisse, M. Rondina, A. Merlo et al., "Reprogramming T lymphocytes for melanoma adoptive immunotherapy by T-cell receptor gene transfer with lentiviral vectors," Cancer Research, vol. 69, no. 24, pp. 9385-9394, 2009.

[144] M. Coccoris, T. Straetemans, C. Govers, C. Lamers, S. Sleijfer, and R. Debets, "T cell receptor (TCR) gene therapy to treat melanoma: lessons from clinical and preclinical studies," Expert Opinion on Biological Therapy, vol. 10, no. 4, pp. 547-562, 2010.

[145] R. A. Morgan, M. E. Dudley, J. R. Wunderlich et al., "Cancer regression in patients after transfer of genetically engineered lymphocytes," Science, vol. 314, no. 5796, pp. 126-129, 2006.

[146] V. Shankaran, H. Ikeda, A. T. Bruce et al., "IFN $\gamma$, and lymphocytes prevent primary tumour development and shape tumour immunogenicity," Nature, vol. 410, no. 6832, pp. 1107-1111, 2001.

[147] C. Bricogne, R. Laranga, A. Padella et al., "Critical mass hypothesis of T cell responses and its application for the treatment of T cell lymphoma," in Hodgkin's and T-Cell Lymphoma: Diagnosis, Treatment Options and Prognosis, W. K. Harvey and R. M. Jacobs, Eds., Nova Publishers, New York, NY, USA, 2012.

[148] K. Karwacz, F. Arce, C. Bricogne, G. Kochan, and D. Escors, "PD-L1 co-stimulation, ligand-induced TCR down-modulation and anti-tumor immunotherapy," Oncoimmunology, vol. 1, no. 1, pp. 86-88, 2012.
[149] K. Karwacz, C. Bricogne, D. MacDonald et al., "PD-L1 costimulation contributes to ligand-induced $\mathrm{T}$ cell receptor downmodulation on $\mathrm{CD}^{+}$T cells," EMBO Molecular Medicine, vol. 3, no. 10, pp. 581-592, 2011.

[150] K. Trnkova, S. Pastorekova, and J. Petrik, "Novel approaches to antiviral and anticancer immunotherapy," Acta Virologica, vol. 56, no. 4, pp. 271-282, 2012.

[151] E. Mohit and S. Rafati, "Chemokine-based immunotherapy: delivery systems and combination therapies," Immunotherapy, no. 8, pp. 807-840, 2012.

[152] S. Ghafouri-Fard, "siRNA and cancer immunotherapy," Immunotherapy, vol. 4, no. 9, pp. 907-917, 2012.

[153] T. Liechtenstein, I. Dufait, A. Lanna, K. Breckpot, and D. Escors, "Modulating co-stimulation during antigen presentation to enhance cancer immunotherapy," Immunology, Endocrine \& Metabolic Agents in Medicinal Chemistry, vol. 12, no. 3, pp. 224235, 2012.

[154] T. Liechtenstein, N. Perez-Janices, C. Bricogne et al., "Immune modulation by genetic modification of dendritic cells with lentiviral vectors," Virus Research, vol. 176, no. 1-2, pp. 1-15, 2013.

[155] D. Escors, C. Bricogne, F. Arce, G. Kochan, and K. Karwacz, "On the Mechanism of $\mathrm{T}$ cell receptor down-modulation and its physiological significance," The Journal of Bioscience and Medicine, vol. 1, no. 1, 2012.

[156] M. R. Parkhurst, J. C. Yang, R. C. Langan et al., "T cells targeting carcinoembryonic antigen can mediate regression of metastatic colorectal cancer but induce severe transient colitis," Molecular Therapy, vol. 19, no. 3, pp. 620-626, 2011.

[157] L. A. Johnson, B. Heemskerk, D. J. Powell Jr. et al., "Gene transfer of tumor-reactive TCR confers both high avidity and tumor reactivity to nonreactive peripheral blood mononuclear cells and tumor-infiltrating lymphocytes," Journal of Immunology, vol. 177, no. 9, pp. 6548-6559, 2006.

[158] M. Schnurr, P. Galambos, C. Scholz et al., "Tumor cell lysatepulsed human dendritic cells induce a T-cell response against pancreatic carcinoma cells: an in vitro model for the assessment of tumor vaccines," Cancer Research, vol. 61, no. 17, pp. 64456450, 2001.

[159] B. Bodey, B. Bodey Jr., S. E. Siegel, and H. E. Kaiser, "Failure of cancer vaccines: the significant limitations of this approach to immunotherapy," Anticancer Research, vol. 20, no. 4, pp. 26652676, 2000.

[160] R. Nurieva, S. Thomas, T. Nguyen et al., "T-cell tolerance or function is determined by combinatorial costimulatory signals," EMBO Journal, vol. 25, no. 11, pp. 2623-2633, 2006.

[161] T. Liechtenstein, I. Dufait, C. Bricogne et al., "PD-L1/PD-1 costimulation, a brake for $\mathrm{T}$ cell activation and a $\mathrm{T}$ cell differentiation signal," Journal of Clinical \& Cellular Immunology, 2012.

[162] L. S. K. Walker, A. Chodos, M. Eggena, H. Dooms, and A. K. Abbas, "Antigen-dependent proliferation of $\mathrm{CD} 4^{+} \mathrm{CD} 25^{+}$ regulatory T cells in vivo," Journal of Experimental Medicine, vol. 198, no. 2, pp. 249-258, 2003.

[163] K. Kretschmer, I. Apostolou, D. Hawiger, K. Khazaie, M. C. Nussenzweig, and H. von Boehmer, "Inducing and expanding regulatory $\mathrm{T}$ cell populations by foreign antigen," Nature Immunology, vol. 6, no. 12, pp. 1219-1227, 2005.

[164] T. Liechtenstein, N. Perez-Janices, and D. Escors, "Lentiviral vectors for cancer immunotherapy and clinical applications," Cancers, vol. 5, no. 3, pp. 815-837, 2013.

[165] S. Sakaguchi, T. Yamaguchi, T. Nomura, and M. Ono, "Regulatory T cells and immune tolerance," Cell, vol. 133, no. 5, pp. 775-787, 2008. 
[166] R. M. Steinman and Z. A. Cohn, "Identification of a novel cell type in peripheral lymphoid organs of mice. I. Morphology, quantitation, tissue distribution," The Journal of Experimental Medicine, vol. 137, no. 5, pp. 1142-1162, 1973.

[167] R. M. Steinman and M. D. Witmer, "Lymphoid dendritic cells are potent stimulators of the primary mixed leukocyte reaction in mice," Proceedings of the National Academy of Sciences of the United States of America, vol. 75, no. 10, pp. 5132-5136, 1978.

[168] M. V. Dhodapkar, R. M. Steinman, J. Krasovsky, C. Munz, and N. Bhardwaj, "Antigen-specific inhibition of effector T cell function in humans after injection of immature dendritic cells," Journal of Experimental Medicine, vol. 193, no. 2, pp. 233-238, 2001.

[169] D. Hawiger, K. Inaba, Y. Dorsett et al., "Dendritic cells induce peripheral $\mathrm{T}$ cell unresponsiveness under steady state conditions in vivo," Journal of Experimental Medicine, vol. 194, no. 6, pp. 769-779, 2001.

[170] K. Inaba, M. Inaba, N. Romani et al., "Generation of large numbers of dendritic cells from mouse bone marrow cultures supplemented with granulocyte/macrophage colony-stimulating factor," Journal of Experimental Medicine, vol. 176, no. 6, pp. 1693-1702, 1992.

[171] L.-J. Zhou and T. F. Tedder, "CD14 ${ }^{+}$blood monocytes can differentiate into functionally mature $\mathrm{CD} 83^{+}$dendritic cells," Proceedings of the National Academy of Sciences of the United States of America, vol. 93, no. 6, pp. 2588-2592, 1996.

[172] S. Tuyaerts, S. M. Noppe, J. Corthals et al., "Generation of large numbers of dendritic cells in a closed system using Cell Factories," Journal of Immunological Methods, vol. 264, no. 1-2, pp. 135-151, 2002.

[173] C. A. Janeway Jr. and K. Bottomly, "Signals and signs for lymphocyte responses," Cell, vol. 76, no. 2, pp. 275-285, 1994.

[174] P. Matzinger, "Tolerance, danger, and the extended family," Annual Review of Immunology, vol. 12, pp. 991-1045, 1994.

[175] M. Dullaers, K. Breckpot, S. Van Meirvenne et al., "Side-byside comparison of lentivirally transduced and mRNA-electroporated dendritic cells: implications for cancer immunotherapy protocols," Molecular Therapy, vol. 10, no. 4, pp. 768-779, 2004.

[176] E. Andreakos, R. O. Williams, J. Wales, B. M. Foxwell, and M. Feldmann, "Activation of NF- $\kappa$ B by the intracellular expression of NF- $\kappa$ B-inducing kinase acts as a powerful vaccine adjuvant," Proceedings of the National Academy of Sciences of the United States of America, vol. 103, no. 39, pp. 14459-14464, 2006.

[177] S. Van Lint, C. Goyvaerts, S. Maenhout et al., "Preclinical evaluation of TriMix and antigen mRNA-based antitumor therapy," Cancer Research, vol. 72, no. 7, pp. 1661-1671, 2012.

[178] K. Karwacz, S. Mukherjee, L. Apolonia et al., "Nonintegrating lentivector vaccines stimulate prolonged T-cell and antibody responses and are effective in tumor therapy," Journal of Virology, vol. 83, no. 7, pp. 3094-3103, 2009.

[179] A. Gruber, J. Kan-Mitchell, K. L. Kuhen, T. Mukai, and F. WongStaal, "Dendritic cells transduced by multiply deleted HIV-1 vectors exhibit normal phenotypes and functions and elicit an HIV-specific cytotoxic T-lymphocyte response in vitro," Blood, vol. 96, no. 4, pp. 1327-1333, 2000.

[180] J. Dyall, J.-B. Latouche, S. Schnell, and M. Sadelain, "Lentivirustransduced human monocyte-derived dendritic cells efficiently stimulate antigen-specific cytotoxic T lymphocytes," Blood, vol. 97, no. 1, pp. 114-121, 2001.

[181] J.-F. Arrighi, M. Pion, M. Wiznerowicz et al., "Lentivirusmediated RNA interference of DC-SIGN expression inhibits human immunodeficiency virus transmission from dendritic cells to T cells," Journal of Virology, vol. 78, no. 20, pp. 1084810855, 2004.

[182] Q. Yu, C. Kovacs, F. Y. Yue, and M. A. Ostrowski, "The role of the p38 mitogen-activated protein kinase, extracellular signalregulated kinase, and phosphoinositide-3-OH kinase signal transduction pathways in CD40 ligand-induced dendritic cell activation and expansion of virus-specific $\mathrm{CD}^{+} \mathrm{T}$ cell memory responses," Journal of Immunology, vol. 172, no. 10, pp. 60476056, 2004.

[183] J. J. Pen, B. De Keersmaecker, S. K. Maenhout et al., "Modulation of regulatory $\mathrm{T}$ cell function by monocyte-derived dendritic cells matured through electroporation with mRNA encoding CD40 ligand, constitutively Active TLR4, and CD70," Journal of Immunology, vol. 191, no. 4, pp. 1976-1983, 2013.

[184] C. Klein, H. Bueler, and R. C. Mulligan, "Comparative analysis of genetically modified dendritic cells and tumor cells as therapeutic cancer vaccines," Journal of Experimental Medicine, vol. 191, no. 10, pp. 1699-1708, 2000.

[185] B. Hu, B. Dai, and P. Wang, "Vaccines delivered by integrationdeficient lentiviral vectors targeting dendritic cells induces strong antigen-specific immunity," Vaccine, vol. 28, no. 41, pp. 6675-6683, 2010.

[186] T. Akazawa, M. Shingai, M. Sasai et al., “Tumor immunotherapy using bone marrow-derived dendritic cells overexpressing Tolllike receptor adaptors," FEBS Letters, vol. 581, no. 18, pp. 33343340, 2007.

[187] K. Breckpot, C. Aerts-Toegaert, C. Heirman et al., "Attenuated expression of A20 markedly increases the efficacy of doublestranded RNA-activated dendritic cells as an anti-cancer vaccine," Journal of Immunology, vol. 182, no. 2, pp. 860-870, 2009.

[188] C. L.-L. Chiang, A. R. Hagemann, R. Leskowitz et al., "Day4 myeloid dendritic cells pulsed with whole tumor lysate are highly immunogenic and elicit potent anti-tumor responses," PLoS ONE, vol. 6, no. 12, Article ID e28732, 2011.

[189] F. Arce, K. Breckpot, H. Stephenson et al., "Selective ERK activation differentiates mouse and human tolerogenic dendritic cells, expands antigen-specific regulatory $\mathrm{T}$ cells, and suppresses experimental inflammatory arthritis," Arthritis and Rheumatism, vol. 63, no. 1, pp. 84-95, 2011.

[190] S. Rutella, S. Danese, and G. Leone, “Tolerogenic dendritic cells: cytokine modulation comes of age," Blood, vol. 108, no. 5, pp. 1435-1440, 2006.

[191] D. Kabelitz, D. Wesch, and H.-H. Oberg, "Regulation of regulatory T cells: role of dendritic cells and toll-like receptors," Critical Reviews in Immunology, vol. 26, no. 4, pp. 291-306, 2006.

[192] M. G. Toscano, M. Delgado, W. Kong, F. Martin, M. Skarica, and D. Ganea, "Dendritic cells transduced with lentiviral vectors expressing vip differentiate into vip-secreting tolerogenic-like DCs," Molecular Therapy, vol. 18, no. 5, pp. 1035-1045, 2010.

[193] J. M. Ilarregui, D. O. Croci, G. A. Bianco et al., “Tolerogenic signals delivered by dendritic cells to T cells through a galectin1-driven immunoregulatory circuit involving interleukin 27 and interleukin 10," Nature Immunology, vol. 10, no. 9, pp. 981-991, 2009.

[194] K. V. Tarbell, L. Petit, X. Zuo et al., "Dendritic cell-expanded, islet-specific $\mathrm{CD} 4{ }^{+} \mathrm{CD} 25^{+} \mathrm{CD}_{2} \mathrm{~L}^{+}$regulatory $\mathrm{T}$ cells restore normoglycemia in diabetic NOD mice," Journal of Experimental Medicine, vol. 204, no. 1, pp. 191-201, 2007.

[195] L. N. Liu, R. Shivakumar, C. Allen, and J. C. Fratantoni, "Delivery of whole tumor lysate into dendritic cells for cancer 
vaccination," Methods in Molecular Biology, vol. 423, pp. 139153, 2008.

[196] J. P. J. J. Hegmans, A. Hemmes, J. G. Aerts, H. C. Hoogsteden, and B. N. Lambrecht, "Immunotherapy of murine malignant mesothelioma using tumor lysate-pulsed dendritic cells," American Journal of Respiratory and Critical Care Medicine, vol. 171, no. 10, pp. 1168-1177, 2005.

[197] N. Herbert, A. Haferkamp, H. F. Schmitz-Winnenthal, and M. Zöller, "Concomitant tumor and autoantigen vaccination supports renal cell carcinoma rejection," Journal of Immunology, vol. 185, no. 2, pp. 902-916, 2010.

[198] B. J. Gitlitz, A. S. Belldegrun, A. Zisman et al., "A pilot trial of tumor lysate-loaded dendritic cells for the treatment of metastatic renal cell carcinoma," Journal of Immunotherapy, vol. 26, no. 5, pp. 412-419, 2003.

[199] H. M. Zarour and J. M. Kirkwood, "Melanoma vaccines: early progress and future promises," Seminars in Cutaneous Medicine and Surgery, vol. 22, no. 1, pp. 68-75, 2003.

[200] M. Leslie, "Solution to vaccine mystery starts to crystallize," Science, vol. 341, no. 6141, pp. 26-27, 2013.

[201] T. L. Flach, G. Ng, A. Hari et al., "Alum interaction with dendritic cell membrane lipids is essential for its adjuvanticity," Nature Medicine, vol. 17, no. 4, pp. 479-487, 2011.

[202] H. Xiao, Y. Peng, Y. Hong et al., "Local administration of TLR ligands rescues the function of tumor-infiltrating CD8 T cells and enhances the antitumor effect of lentivector immunization," Journal of Immunology, vol. 190, no. 11, pp. 5866-5873, 2013.

[203] S. N. Lim, S. Kuhn, E. Hyde, and F. Ronchese, "Combined TLR stimulation with Pam3Cys and Poly I: C enhances Flt3-ligand dendritic cell activation for tumor immunotherapy," Journal of Immunotherapy, vol. 35, no. 9, pp. 670-679, 2012.

[204] T. Kawai and S. Akira, "Toll-like receptor and RIG-1-like receptor signaling," Annals of the New York Academy of Sciences, vol. 1143, pp. 1-20, 2008.

[205] B. Coornaert, I. Carpentier, and R. Beyaert, "A20: central gatekeeper in inflammation and immunity," Journal of Biological Chemistry, vol. 284, no. 13, pp. 8217-8221, 2009.

[206] X.-T. Song, K. E. Kabler, L. Shen, L. Rollins, X. F. Huang, and S.-Y. Chen, "A20 is an antigen presentation attenuator, and its inhibition overcomes regulatory T cell-mediated suppression," Nature Medicine, vol. 14, no. 3, pp. 258-265, 2008.

[207] T. Yokosuka, M. Takamatsu, W. Kobayashi-Imanishi, A. Hashimoto-Tane, M. Azuma, and T. Saito, "Programmed cell death 1 forms negative costimulatory microclusters that directly inhibit $\mathrm{T}$ cell receptor signaling by recruiting phosphatase SHP2," Journal of Experimental Medicine, vol. 209, no. 6, pp. 1201-1217, 2012.

[208] M. R. Junttila, S.-P. Li, and J. Westermarck, "Phosphatasemediated crosstalk between MAPK signaling pathways in the regulation of cell survival," FASEB Journal, vol. 22, no. 4, pp. 954-965, 2008.

[209] Q. Zhao, X. Wang, L. D. Nelin et al., "MAP kinase phosphatase 1 controls innate immune responses and suppresses endotoxic shock," Journal of Experimental Medicine, vol. 203, no. 1, pp. 131140, 2006

[210] K. V. Salojin, I. B. Owusu, K. A. Millerchip, M. Potter, K. A. Platt, and T. Oravecz, "Essential role of MAPK phosphatase-1 in the negative control of innate immune responses," Journal of Immunology, vol. 176, no. 3, pp. 1899-1907, 2006.

[211] M. Hammer, J. Mages, H. Dietrich et al., "Dual specificity phosphatase 1 (DUSP1) regulates a subset of LPS-induced genes and protects mice from lethal endotoxin shock," Journal of Experimental Medicine, vol. 203, no. 1, pp. 15-20, 2006.

[212] S. Saccani, S. Pantano, and G. Natoli, "p38-dependent marking of inflammatory genes for increased NF- $\kappa$ B recruitment," Nature Immunology, vol. 3, no. 1, pp. 69-75, 2002.

[213] A. Shimizu, M. Baratchian, Y. Takeuchi et al., "Kaposi's sarcoma-associated herpesvirus vFLIP and human T cell lymphotropic virus type 1 Tax oncogenic proteins activate $I \kappa B$ kinase subunit $\gamma$ by different mechanisms independent of the physiological cytokine-induced pathways," Journal of Virology, vol. 85, no. 14, pp. 7444-7448, 2011.

[214] N. Field, W. Low, M. Daniels et al., "KSHV vFLIP binds to IKK$\gamma$ to activate IKK," Journal of Cell Science, vol. 116, no. 18, pp. 3721-3728, 2003.

[215] C. Bagnéris, A. V. Ageichik, N. Cronin et al., "Crystal structure of a vFlip-IKK $\gamma$ complex: insights into viral activation of the IKK signalosome," Molecular Cell, vol. 30, no. 5, pp. 620-631, 2008.

[216] H. M. Rowe, L. Lopes, N. Brown et al., "Expression of vFLIP in a lentiviral vaccine vector activates NF- $\kappa \mathrm{B}$, matures dendritic cells, and increases CD8 ${ }^{+}$T-cell responses," Journal of Virology, vol. 83, no. 4, pp. 1555-1562, 2009.

[217] I. E. Wartz, K. M. O’Rourke, H. Zhou et al., "De-ubiquitination and ubiquitin ligase domains of A20 downregulate NF- $\kappa$ B signalling," Nature, vol. 430, no. 7000, pp. 694-699, 2004.

[218] R. Beyaert, K. Heyninck, and S. Van Huffel, "A20 and A20binding proteins as cellular inhibitors of nuclear factor- $\kappa \mathrm{B}$ dependent gene expression and apoptosis," Biochemical Pharmacology, vol. 60, no. 8, pp. 1143-1151, 2000.

[219] S. Q. Zhang, A. Kovalenko, G. Cantarella, and D. Wallach, "Recruitment of the IKK signalosome to the p55 TNF receptor: RIP and A20 bind to NEMO (IKK $\gamma$ ) upon receptor stimulation," Immunity, vol. 12, no. 3, pp. 301-311, 2000.

[220] K. Heyninck and R. Beyaert, "The cytokine-inducible zinc finger protein A20 inhibits IL-1-induced NF- $\kappa$ B activation at the level of TRAF6," FEBS Letters, vol. 442, no. 2-3, pp. 147-150, 1999.

[221] D. L. Boone, E. E. Turer, E. G. Lee et al., "The ubiquitinmodifying enzyme A20 is required for termination of Toll-like receptor responses," Nature Immunology, vol. 5, no. 10, pp. 10521060,2004

[222] K. Sato, H. Nagayama, K. Tadokoro, T. Juji, and T. A. Takahashi, "Extracellular signal-regulated kinase, stress-activated protein kinase/c-Jun N-terminal kinase, and p38(mapk) are involved in IL-10-mediated selective repression of TNF- $\alpha$-induced activation and maturation of human peripheral blood monocytederived dendritic cells," Journal of Immunology, vol. 162, no. 7, pp. 3865-3872, 1999.

[223] K. M. Ardeshna, A. R. Pizzey, S. Devereux, and A. Khwaja, "The PI3 kinase, p38 SAP kinase, and NF- $\kappa$ b signal transduction pathways are involved in the survival and maturation of lipopolysaccharide-stimulated human monocyte-derived dendritic cells," Blood, vol. 96, no. 3, pp. 1039-1046, 2000.

[224] J.-F. Arrighi, M. Rebsamen, F. Rousset, V. Kindler, and C. Hauser, "A critical role for p38 mitogen-activated protein kinase in the maturation of human blood-derived dendritic cells induced by lipopolysaccharide, TNF- $\alpha$, and contact sensitizers," Journal of Immunology, vol. 166, no. 6, pp. 3837-3845, 2001.

[225] J. Raingeaud, A. J. Whitmarsh, T. Barrett, B. Dérijard, and R. J. Davis, "MKK3- and MKK6-regulated gene expression is mediated by the p38 mitogen-activated protein kinase signal 
transduction pathway," Molecular and Cellular Biology, vol. 16, no. 3, pp. 1247-1255, 1996.

[226] Z. Yang, X. Zhang, P. A. Darrah, and D. M. Mosser, "The regulation of Th1 responses by the p38 MAPK," Journal of Immunology, vol. 185, no. 10, pp. 6205-6213, 2010.

[227] H. A. Franks, Q. Wang, S. J. Lax et al., "Novel function for the p38-MK2 signalling pathway in circulating CD1c+ (BDCA-1+) myeloid dendritic cells from healthy donors and advanced cancer patients, inhibition of p38 enhances IL-12 whilst suppressing IL-10," International Journal of Cancer, 2013.

[228] H. Firat, F. Garcia-Pons, S. Tourdot et al., "H-2 class I knockout, HLA-A2. 1-transgenic mice: a versatile animal model for preclinical evaluation of antitumor immunotherapeutic strategies," European Journal of Immunology, vol. 29, no. 10, pp. 3112-3121, 1999.

[229] E. Kriehuber, W. Bauer, A.-S. Charbonnier et al., "Balance between NF- $\kappa$ B and JNK/AP-1 activity controls dendritic cell life and death," Blood, vol. 106, no. 1, pp. 175-183, 2005.

[230] T. Nakahara, H. Uchi, K. Urabe, Q. Chen, M. Furue, and Y. Moroi, "Role of c-Jun N-terminal kinase on lipopolysaccharide induced maturation of human monocyte-derived dendritic cells," International Immunology, vol. 16, no. 12, pp. 1701-1709, 2004.

[231] K. Lei, A. Nimnual, W.-X. Zong et al., "The Bax subfamily of $\mathrm{Bcl} 2$-related proteins is essential for apoptotic signal transduction by c-Jun $\mathrm{NH}_{2}$-terminal kinase," Molecular and Cellular Biology, vol. 22, no. 13, pp. 4929-4942, 2002.

[232] M. Dupage, C. Mazumdar, L. M. Schmidt, A. F. Cheung, and T. Jacks, "Expression of tumour-specific antigens underlies cancer immunoediting," Nature, vol. 482, no. 7385, pp. 405-409, 2012.

[233] A. D. Griesemer, E. C. Sorenson, and M. A. Hardy, “The role of the thymus in tolerance," Transplantation, vol. 90, no. 5, pp. 465-474, 2010.

[234] F. Flores-Borja, C. Mauri, and M. R. Ehrenstein, "Restoring the balance: harnessing regulatory T cells for therapy in rheumatoid arthritis," European Journal of Immunology, vol. 38, no. 4, pp. 934-937, 2008.

[235] R. R. Rich and C. W. Pierce, "Biological expressions of lymphocyte activation. II. Generation of a population of thymusderived suppressor lymphocytes," Journal of Experimental Medicine, vol. 137, no. 3, pp. 649-659, 1973.

[236] E. Simpson and H. Cantor, "Regulation of the immune response by subclasses of T lymphocytes. II. The effect of adult thymectomy upon humoral and cellular responses in mice," European Journal of Immunology, vol. 5, no. 5, pp. 337-343, 1975.

[237] H. Cantor and E. Simpson, "Regulation of the immune response by subclasses of $\mathrm{T}$ lymphocytes. I. Interactions between pre killer $\mathrm{T}$ cells and regulatory $\mathrm{T}$ cells obtained from peripheral lymphoid tissues of mice," European Journal of Immunology, vol. 5, no. 5, pp. 330-336, 1975.

[238] T. Y. H. Tai You Ha, B. H. Waksman, and H. P. Treffers, “The thymic suppressor cell. I. Separation of subpopulations with suppressor activity," Journal of Experimental Medicine, vol. 139, no. 1, pp. 13-23, 1974.

[239] M. J. Taussig, "Demonstration of suppressor $\mathrm{T}$ cells in a population of 'educated' T cells," Nature, vol. 248, no. 5445, pp. 236-238, 1974.

[240] L. Polak and J. L. Turk, "Reversal of immunological tolerance by cyclophosphamide through inhibition of suppressor cell activity," Nature, vol. 249, no. 5458, pp. 654-656, 1974.
[241] S. Kan, S. Hazama, K. Maeda et al., "Suppressive effects of cyclophosphamide and gemcitabine on regulatory T-cell induction in vitro," Anticancer Research, vol. 32, no. 12, pp. 5363-5369, 2012.

[242] H. Kirchner, T. M. Chused, and R. B. Herberman, "Evidence of suppressor cell activity in spleens of mice bearing primary tumors induced by Moloney sarcoma virus," Journal of Experimental Medicine, vol. 139, no. 6, pp. 1473-1487, 1974.

[243] D. I. Gabrilovich, V. Bronte, S.-H. Chen et al., "The terminology issue for myeloid-derived suppressor cells," Cancer Research, vol. 67, no. 1, article 425, 2007.

[244] A. Basten, J. F. A. P. Miller, J. Sprent, and C. Cheers, "Cell to cell interaction in the immune response. X. T cell dependent suppression in tolerant mice," Journal of Experimental Medicine, vol. 140, no. 1, pp. 199-217, 1974.

[245] D. M. Sansom, "CD28, CTLA-4 and their ligands: who does what and to whom?" Immunology, vol. 101, no. 2, pp. 169-177, 2000.

[246] O. S. Qureshi, Y. Zheng, K. Nakamura et al., "Trans-endocytosis of CD80 and CD86: a molecular basis for the cell-extrinsic function of CTLA-4," Science, vol. 332, no. 6029, pp. 600-603, 2011.

[247] L. S. K. Walker and D. M. Sansom, "The emerging role of CTLA4 as a cell-extrinsic regulator of T cell responses," Nature Reviews Immunology, vol. 11, no. 12, pp. 852-863, 2011.

[248] S. Hori, T. Nomura, and S. Sakaguchi, "Control of regulatory T cell development by the transcription factor Foxp3," Science, vol. 299, no. 5609, pp. 1057-1061, 2003.

[249] J. Schwaber and E. P. Cohen, "Human X mouse somatic cell hybrid clone secreting immunoglobulins of both parental types," Nature, vol. 244, no. 5416, pp. 444-447, 1973.

[250] S. Sakaguchi, "The origin of FOXP3-expressing CD4 ${ }^{+}$regulatory T cells: thymus or periphery," Journal of Clinical Investigation, vol. 112, no. 9, pp. 1310-1312, 2003.

[251] X. C. Li, G. Demirci, S. Ferrari-Lacraz et al., "IL-15 and IL-2: a matter of life and death for T cells in vivo," Nature Medicine, vol. 7, no. 1, pp. 114-118, 2001.

[252] A. Scheffold, J. Hühn, and T. Höfer, "Regulation of CD $4^{+} \mathrm{CD} 25^{+}$ regulatory T cell activity: it takes (IL-)two to tango," European Journal of Immunology, vol. 35, no. 5, pp. 1336-1341, 2005.

[253] J. D. Fontenot, J. P. Rasmussen, M. A. Gavin, and A. Y. Rudensky, "A function for interleukin 2 in Foxp3-expressing regulatory T cells," Nature Immunology, vol. 6, no. 11, pp. 1142-1151, 2005.

[254] D. Getnet, J. F. Grosso, M. V. Goldberg et al., "A role for the transcription factor Helios in human $\mathrm{CD} 4{ }^{+} \mathrm{CD} 25^{+}$regulatory T cells," Molecular Immunology, vol. 47, no. 7-8, pp. 1595-1600, 2010.

[255] P. Chappert, M. Leboeuf, P. Rameau et al., "Antigen-driven interactions with dendritic cells and expansion of Foxp3+ regulatory T cells occur in the absence of inflammatory signals," Journal of Immunology, vol. 180, no. 1, pp. 327-334, 2008.

[256] K. Mahnke, Y. Qian, J. Knop, and A. H. Enk, "Induction of $\mathrm{CD} 4^{+} / \mathrm{CD} 25^{+}$regulatory $\mathrm{T}$ cells by targeting of antigens to immature dendritic cells," Blood, vol. 101, no. 12, pp. 4862-4869, 2003.

[257] L. Wang, K. Pino-Lagos, V. C. De Vries, I. Guleria, M. H. Sayegh, and R. J. Noelle, "Programmed death 1 ligand signaling regulates the generation of adaptive Foxp $3^{+} \mathrm{CD} 4^{+}$regulatory T cells," Proceedings of the National Academy of Sciences of the United States of America, vol. 105, no. 27, pp. 9331-9336, 2008. 
[258] S. You, B. Leforban, C. Garcia, J.-F. Bach, J. A. Bluestone, and L. Chatenoud, "Adaptive TGF- $\beta$-dependent regulatory T cells control autoimmune diabetes and are a privileged target of antiCD3 antibody treatment," Proceedings of the National Academy of Sciences of the United States of America, vol. 104, no. 15, pp. 6335-6340, 2007.

[259] O. Akbari, G. J. Freeman, E. H. Meyer et al., "Antigen-specific regulatory $\mathrm{T}$ cells develop via the ICOS-ICOS-ligand pathway and inhibit allergen-induced airway hyperreactivity," Nature Medicine, vol. 8, no. 9, pp. 1024-1032, 2002.

[260] A. O’Garra, P. L. Vieira, P. Vieira, and A. E. Goldfeld, "IL10-producing and naturally occurring $\mathrm{CD} 4^{+}$Tregs: limiting collateral damage," Journal of Clinical Investigation, vol. 114, no. 10, pp. 1372-1378, 2004.

[261] E.-O. Glocker, D. Kotlarz, K. Boztug et al., "Inflammatory bowel disease and mutations affecting the interleukin-10 receptor," The New England Journal of Medicine, vol. 361, no. 21, pp. 2033-2045, 2009.

[262] S. Onizuka, I. Tawara, J. Shimizu, S. Sakaguchi, T. Fujita, and E. Nakayama, "Tumor rejection by in vivo administration of antiCD25 (interleukin-2 receptor $\alpha$ ) monoclonal antibody," Cancer Research, vol. 59, no. 13, pp. 3128-3133, 1999.

[263] G. Zhou, C. G. Drake, and H. I. Levitsky, "Amplification of tumor-specific regulatory $\mathrm{T}$ cells following therapeutic cancer vaccines," Blood, vol. 107, no. 2, pp. 628-636, 2006.

[264] A. M. Wolf, D. Wolf, M. Steurer, G. Gastl, E. Gunsilius, and B. Grubeck-Loebenstein, "Increase of regulatory T cells in the peripheral blood of cancer patients," Clinical Cancer Research, vol. 9, no. 2, pp. 606-612, 2003.

[265] H. Y. Wang, D. A. Lee, G. Peng et al., "Tumor-specific human $\mathrm{CD}^{+}$regulatory $\mathrm{T}$ cells and their ligands: implications for immunotherapy," Immunity, vol. 20, no. 1, pp. 107-118, 2004.

[266] M. Beyer and J. L. Schultze, "Regulatory T cells in cancer," Blood, vol. 108, no. 3, pp. 804-811, 2006.

[267] A. Gallimore and A. Godkin, "Regulatory T cells and tumour immunity-observations in mice and men," Immunology, vol. 123, no. 2, pp. 157-163, 2008.

[268] T. L. Whiteside, P. Schuler, and B. Schilling, "Induced and natural regulatory T cells in human cancer," Expert Opinion on Biological Therapy, vol. 12, no. 10, pp. 1383-1397, 2012.

[269] F. Ghiringhelli, P. E. Puig, S. Roux et al., "Tumor cells convert immature myeloid dendritic cells into TGF- $\beta$-secreting cells inducing $\mathrm{CD}^{+} \mathrm{CD} 25^{+}$regulatory T cell proliferation," Journal of Experimental Medicine, vol. 202, no. 7, pp. 919-929, 2005.

[270] S. Sharma, S.-C. Yang, L. Zhu et al., "Tumor cyclooxygenase2/prostaglandin $\mathrm{E}_{2}$-dependent promotion of FOXP3 expression and $\mathrm{CD} 4^{+} \mathrm{CD} 25^{+} \mathrm{T}$ regulatory cell activities in lung cancer," Cancer Research, vol. 65, no. 12, pp. 5211-5220, 2005.

[271] E. Schlecker, A. Stojanovic, C. Eisen et al., “Tumor-infiltrating monocytic myeloid-derived suppressor cells mediate CCR5dependent recruitment of regulatory $\mathrm{T}$ cells favoring tumor growth," Journal of Immunology, vol. 189, no. 12, pp. 5602-5611, 2012.

[272] M. L. Belladonna, C. Orabona, U. Grohmann, and P. Puccetti, "TGF- $\beta$ and kynurenines as the key to infectious tolerance," Trends in Molecular Medicine, vol. 15, no. 2, pp. 41-49, 2009.

[273] S. P. Cobbold, E. Adams, C. A. Farquhar et al., "Infectious tolerance via the consumption of essential amino acids and mTOR signaling," Proceedings of the National Academy of Sciences of the United States of America, vol. 106, no. 29, pp. 12055-12060, 2009.
[274] F. Flores-Borja, E. C. Jury, C. Mauri, and M. R. Ehrenstein, "Defects in CTLA-4 are associated with abnormal regulatory T cell function in rheumatoid arthritis," Proceedings of the National Academy of Sciences of the United States of America, vol. 105, no. 49, pp. 19396-19401, 2008.

[275] A. V. Collins, D. W. Brodie, R. J. C. Gilbert et al., "The interaction properties of costimulatory molecules revisited," Immunity, vol. 17, no. 2, pp. 201-210, 2002.

[276] R. Nasser, M. Pelegrin, M. Plays, L. Gros, and M. Piechaczyk, "Control of regulatory $\mathrm{T}$ cells is necessary for vaccine-like effects of antiviral immunotherapy by monoclonal antibodies," Blood, vol. 121, no. 7, pp. 1102-1111, 2013.

[277] R. P. M. Sutmuller, L. M. Van Duivenvoorde, A. Van Elsas et al., "Synergism of cytotoxic T lymphocyte-associated antigen 4 blockade and depletion of $\mathrm{CD}_{2} 5^{+}$regulatory $\mathrm{T}$ cells in antitumor therapy reveals alternative pathways for suppression of autoreactive cytotoxic T lymphocyte responses," Journal of Experimental Medicine, vol. 194, no. 6, pp. 823-832, 2001.

[278] J. Duraiswamy, K. M. Kaluza, G. J. Freeman, and G. Coukos, "Dual blockade of PD-1 and CTLA-4 combined with tumor vaccine effectively restores t-cell rejection function in tumors," Cancer Research, vol. 73, no. 12, pp. 3591-3603, 2013.

[279] D. R. Leach, M. F. Krummel, and J. P. Allison, "Enhancement of antitumor immunity by CTLA-4 blockade," Science, vol. 271, no. 5256, pp. 1734-1736, 1996.

[280] V. A. Trinh and W. J. Hwu, "Ipilimumab in the treatment of melanoma," Expert Opinion on Biological Therapy, vol. 12, no. 6, pp. 773-782, 2012.

[281] F. S. Hodi, D. A. Oble, J. Drappatz et al., "CTLA-4 blockade with ipilimumab induces significant clinical benefit in a female with melanoma metastases to the CNS," Nature Clinical Practice Oncology, vol. 5, no. 9, pp. 557-561, 2008.

[282] F. S. Hodi, S. J. O’Day, D. F. McDermott et al., "Improved survival with ipilimumab in patients with metastatic melanoma," The New England Journal of Medicine, vol. 363, no. 8, pp. 711723, 2010.

[283] P. Tomasini, N. Khobta, L. Greillier, and F. Barlesi, "Ipilimumab: its potential in non-small cell lung cancer," Therapeutic Advances in Medical Oncology, vol. 4, no. 2, pp. 43-50, 2012.

[284] T. R. Simpson, F. Li, W. Montalvo-Ortiz et al., "Fc-dependent depletion of tumor-infiltrating regulatory $\mathrm{T}$ cells co-defines the efficacy of anti-CTLA-4 therapy against melanoma," Journal of Experimental Medicine, vol. 210, no. 9, pp. 1695-1710, 2013.

[285] R. E. Royal, C. Levy, K. Turner et al., "Phase 2 trial of single agent ipilimumab (Anti-CTLA-4) for locally advanced or metastatic pancreatic adenocarcinoma," Journal of Immunotherapy, vol. 33, no. 8, pp. 828-833, 2010.

[286] S. A. Quezada, K. S. Peggs, M. A. Curran, and J. P. Allison, "CTLA4 blockade and GM-CSF combination immunotherapy alters the intratumor balance of effector and regulatory T cells," Journal of Clinical Investigation, vol. 116, no. 7, pp. 1935-1945, 2006.

[287] J. H. Finke, B. Rini, J. Ireland et al., "Sunitinib reverses type-1 immune suppression and decreases T-regulatory cells in renal cell carcinoma patients," Clinical Cancer Research, vol. 14, no. 20, pp. 6674-6682, 2008.

[288] H. Xin, C. Zhang, A. Herrmann, Y. Du, R. Figlin, and H. $\mathrm{Yu}$, "Sunitinib inhibition of Stat3 induces renal cell carcinoma tumor cell apoptosis and reduces immunosuppressive cells," Cancer Research, vol. 69, no. 6, pp. 2506-2513, 2009.

[289] C. Nishioka, T. Ikezoe, J. Yang et al., "Blockade of MEK/ERK signaling enhances sunitinib-induced growth inhibition and 
apoptosis of leukemia cells possessing activating mutations of the FLT3 gene," Leukemia Research, vol. 32, no. 6, pp. 865-872, 2008.

[290] P. J. Roberts and C. J. Der, "Targeting the Raf-MEK-ERK mitogen-activated protein kinase cascade for the treatment of cancer," Oncogene, vol. 26, no. 22, pp. 3291-3310, 2007.

[291] Y. Hailemichael, Z. Dai, N. Jaffarzad et al., "Persistent antigen at vaccination sites induces tumor-specific $\mathrm{CD} 8{ }^{+} \mathrm{T}$ cell sequestration, dysfunction and deletion," Nature Medicine, vol. 19, no. 4, pp. 465-472, 2013.

[292] D. I. Gabrilovich and S. Nagaraj, "Myeloid-derived suppressor cells as regulators of the immune system," Nature Reviews Immunology, vol. 9, no. 3, pp. 162-174, 2009.

[293] T. Condamine and D. I. Gabrilovich, "Molecular mechanisms regulating myeloid-derived suppressor cell differentiation and function," Trends in Immunology, vol. 32, no. 1, pp. 19-25, 2011.

[294] C. Iclozan, S. Antonia, A. Chiappori, D. T. Chen, and D. Gabrilovich, "Therapeutic regulation of myeloid-derived suppressor cells and immune response to cancer vaccine in patients with extensive stage small cell lung cancer," Cancer Immunology, Immunotherapy, vol. 62, no. 5, pp. 909-918, 2013.

[295] G. A. Rabinovich, D. Gabrilovich, and E. M. Sotomayor, "Immunosuppressive strategies that are mediated by tumor cells," Annual Review of Immunology, vol. 25, pp. 267-296, 2007.

[296] M. B. Lutz, N. A. Kukutsch, M. Menges, S. Rossner, and G. Schuler, "Culture of bone marrow cells in GM-CSF plus high doses of lipopolysaccharide generates exclusively immature dendritic cells which induce alloantigen-specific CD4 T cell anergy in vitro," European Journal of Immunology, vol. 30, no. 4, pp. 1048-1052, 2000.

[297] P. Cheng, C. A. Corzo, N. Luetteke et al., "Inhibition of dendritic cell differentiation and accumulation of myeloid-derived suppressor cells in cancer is regulated by S100A9 protein," Journal of Experimental Medicine, vol. 205, no. 10, pp. 2235-2249, 2008.

[298] J.-I. Youn, S. Nagaraj, M. Collazo, and D. I. Gabrilovich, "Subsets of myeloid-derived suppressor cells in tumor-bearing mice," Journal of Immunology, vol. 181, no. 8, pp. 5791-5802, 2008.

[299] S. Solito, V. Bronte, and S. Mandruzzato, "Antigen specificity of immune suppression by myeloid-derived suppressor cells," Journal of Leukocyte Biology, vol. 90, no. 1, pp. 31-36, 2011.

[300] M. K. Srivastava, P. Sinha, V. K. Clements, P. Rodriguez, and S. Ostrand-Rosenberg, "Myeloid-derived suppressor cells inhibit T-cell activation by depleting cystine and cysteine," Cancer Research, vol. 70, no. 1, pp. 68-77, 2010.

[301] V. Bronte, E. Apolloni, A. Cabrelle et al., "Identification of a $\mathrm{CD} 1 \mathrm{~b}^{+} / \mathrm{Gr}-1^{+} / \mathrm{CD} 31^{+}$myeloid progenitor capable of activating or suppressing $\mathrm{CD}^{+}$T cells," Blood, vol. 96, no. 12, pp. 38383846, 2000.

[302] P. Serafini, K. Meckel, M. Kelso et al., "Phosphodiesterase5 inhibition augments endogenous antitumor immunity by reducing myeloid-derived suppressor cell function," Journal of Experimental Medicine, vol. 203, no. 12, pp. 2691-2702, 2006.

[303] J. K. Morales, M. Kmieciak, K. L. Knutson, H. D. Bear, and M. H. Manjili, "GM-CSF is one of the main breast tumor-derived soluble factors involved in the differentiation of CD11b-Gr1bone marrow progenitor cells into myeloid-derived suppressor cells," Breast Cancer Research and Treatment, vol. 123, no. 1, pp. 39-49, 2010.

[304] L. Dolcetti, E. Peranzoni, S. Ugel et al., "Hierarchy of immunosuppressive strength among myeloid-derived suppressor cell subsets is determined by GM-CSF," European Journal of Immunology, vol. 40, no. 1, pp. 22-35, 2010.
[305] E. J. Small, D. M. Reese, B. Um, S. Whisenant, S. C. Dixon, and W. D. Figg, "Therapy of advanced prostate cancer with granulocyte macrophage colony-stimulating factor," Clinical Cancer Research, vol. 5, no. 7, pp. 1738-1744, 1999.

[306] M. J. Mastrangelo, H. C. Maguire Jr., L. C. Eisenlohr et al., "Intratumoral recombinant GM-CSF-encoding virus as gene therapy in patients with cutaneous melanoma," Cancer Gene Therapy, vol. 6, no. 5, pp. 409-422, 1999.

[307] G. Dranoff, "GM-CSF-secreting melanoma vaccines," Oncogene, vol. 22, no. 20, pp. 3188-3192, 2003.

[308] B. H. Kushner and N.-K. V. Cheung, "GM-CSF enhances 3F8 monoclonal antibody-dependent cellular cytotoxicity against human melanoma and neuroblastoma," Blood, vol. 73, no. 7, pp. 1936-1941, 1989.

[309] P. Rössner, J. Bubeník, V. Sobotá et al., “Granulocytemacrophage colony-stimulating factor-producing tumour vaccines," Folia Biologica, vol. 45, no. 5, pp. 173-177, 1999.

[310] C. M. Gutschalk, A. K. Yanamandra, N. Linde, A. Meides, S. Depner, and M. M. Mueller, "GM-CSF enhances tumor invasion by elevated MMP-2, -9, and -26 expression," Cancer Medicine, vol. 2, no. 2, pp. 117-129, 2012.

[311] M. Martinez, N. Ono, M. Planutiene, K. Planutis, E. L. Nelson, and R. F. Holcombe, "Granulocyte-macrophage stimulating factor (GM-CSF) increases circulating dendritic cells but does not abrogate suppression of adaptive cellular immunity in patients with metastatic colorectal cancer receiving chemotherapy," Cancer Cell International, vol. 12, article 2, 2012.

[312] I. Marigo, E. Bosio, S. Solito et al., "Tumor-induced tolerance and immune suppression depend on the C/EBP $\beta$ transcription factor," Immunity, vol. 32, no. 6, pp. 790-802, 2010.

[313] M. G. Lechner, D. J. Liebertz, and A. L. Epstein., "Characterization of cytokine-induced myeloid-derived suppressor cells from normal human peripheral blood mononuclear cells," Journal of Immunology, vol. 185, no. 4, pp. 2273-2284, 2010.

[314] S. L. Highfill, P. C. Rodriguez, Q. Zhou et al., "Bone marrow myeloid-derived suppressor cells (MDSCs) inhibit graft-versushost disease (GVHD) via an arginase-1-dependent mechanism that is up-regulated by interleukin-13," Blood, vol. 116, no. 25, pp. 5738-5747, 2010.

[315] J. Dulos, G. J. Carven, S. J. Van Boxtel et al., "PD-1 blockade augments Th1 and Th17 and suppresses Th2 responses in peripheral blood from patients with prostate and advanced melanoma cancer," Journal of Immunotherapy, vol. 35, no. 2, pp. 169-178, 2012.

[316] H. Navabi, B. Jasani, A. Reece et al., "A clinical grade poly I:Canalogue (Ampligen) promotes optimal DC maturation and Th1-type T cell responses of healthy donors and cancer patients in vitro," Vaccine, vol. 27, no. 1, pp. 107-115, 2009.

[317] X. Xiang, A. Poliakov, C. Liu et al., "Induction of myeloidderived suppressor cells by tumor exosomes," International Journal of Cancer, vol. 124, no. 11, pp. 2621-2633, 2009.

[318] R. Valenti, V. Huber, P. Filipazzi et al., "Human tumor-released microvesicles promote the differentiation of myeloid cells with transforming growth factor- $\beta$-mediated suppressive activity on T lymphocytes," Cancer Research, vol. 66, no. 18, pp. 9290-9298, 2006.

[319] N. Obermajer, R. Muthuswamy, J. Lesnock, R. P. Edwards, and P. Kalinski, "Positive feedback between PGE2 and COX2 redirects the differentiation of human dendritic cells toward stable myeloid-derived suppressor cells," Blood, vol. 118, no. 20, pp. 5498-5505, 2011. 
[320] P. U. Emeagi, S. Maenhout, N. Dang, C. Heirman, K. Thielemans, and K. Breckpot, "Downregulation of Stat3 in melanoma: reprogramming the immune microenvironment as an anticancer therapeutic strategy," Gene Therapy, 2013.

[321] J. I. Youn, V. Kumar, M. Collazo et al., "Epigenetic silencing of retinoblastoma gene regulates pathologic differentiation of myeloid cells in cancer," Nature Immunology, vol. 14, no. 3, pp. 211-220, 2013.

[322] E. Peranzoni, S. Zilio, I. Marigo et al., "Myeloid-derived suppressor cell heterogeneity and subset definition," Current Opinion in Immunology, vol. 22, no. 2, pp. 238-244, 2010.

[323] E. Apolloni, V. Bronte, A. Mazzoni et al., "Immortalized myeloid suppressor cells trigger apoptosis in antigen-activated T lymphocytes," Journal of Immunology, vol. 165, no. 12, pp. 67236730, 2000. 


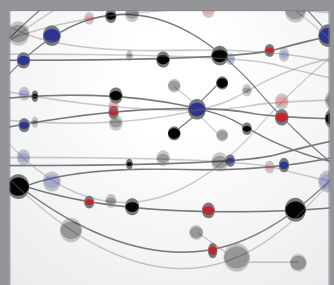

The Scientific World Journal
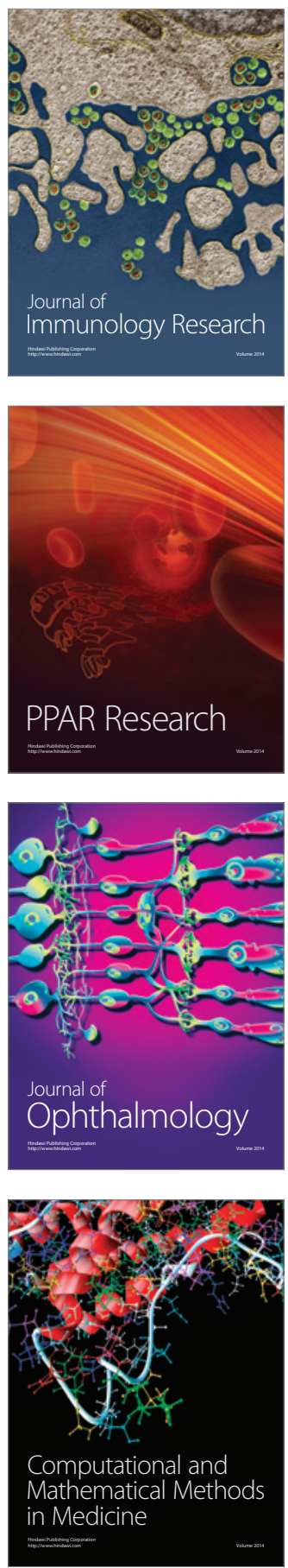

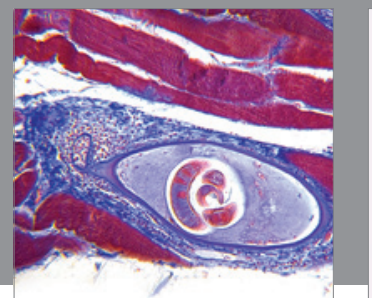

Gastroenterology

Research and Practice
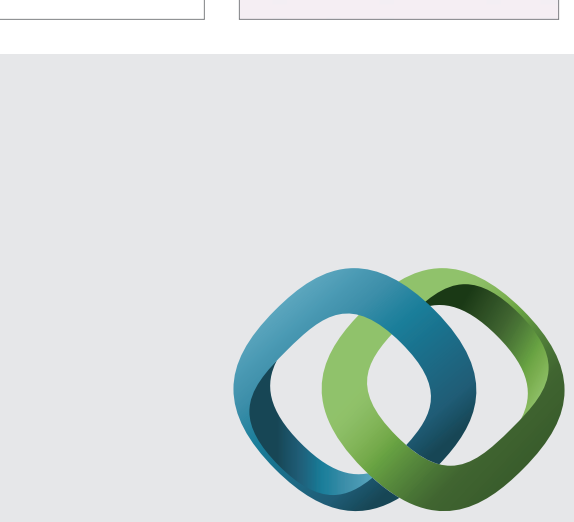

\section{Hindawi}

Submit your manuscripts at

http://www.hindawi.com
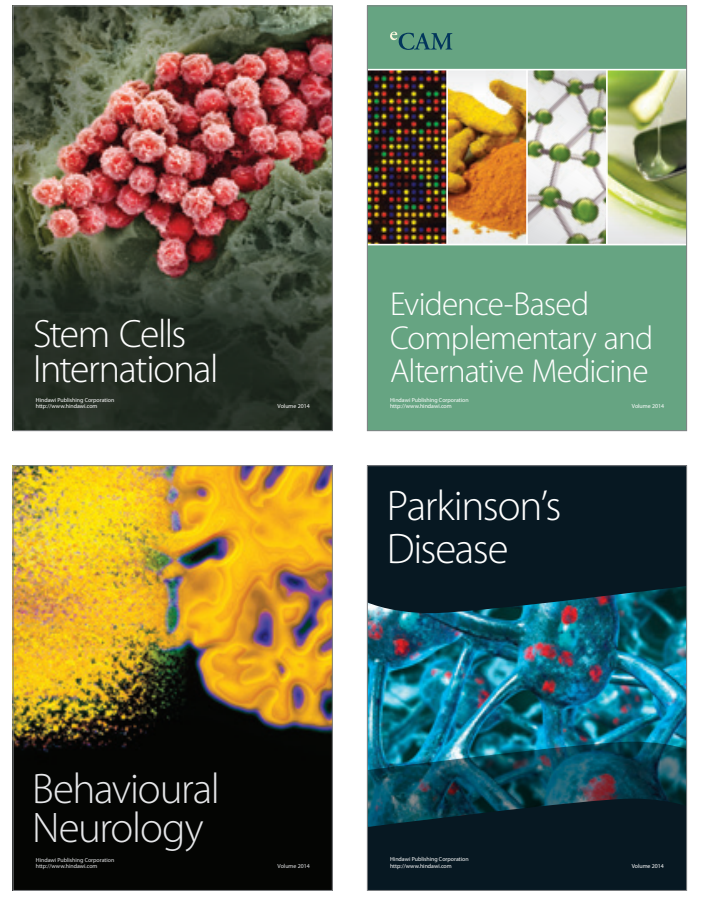
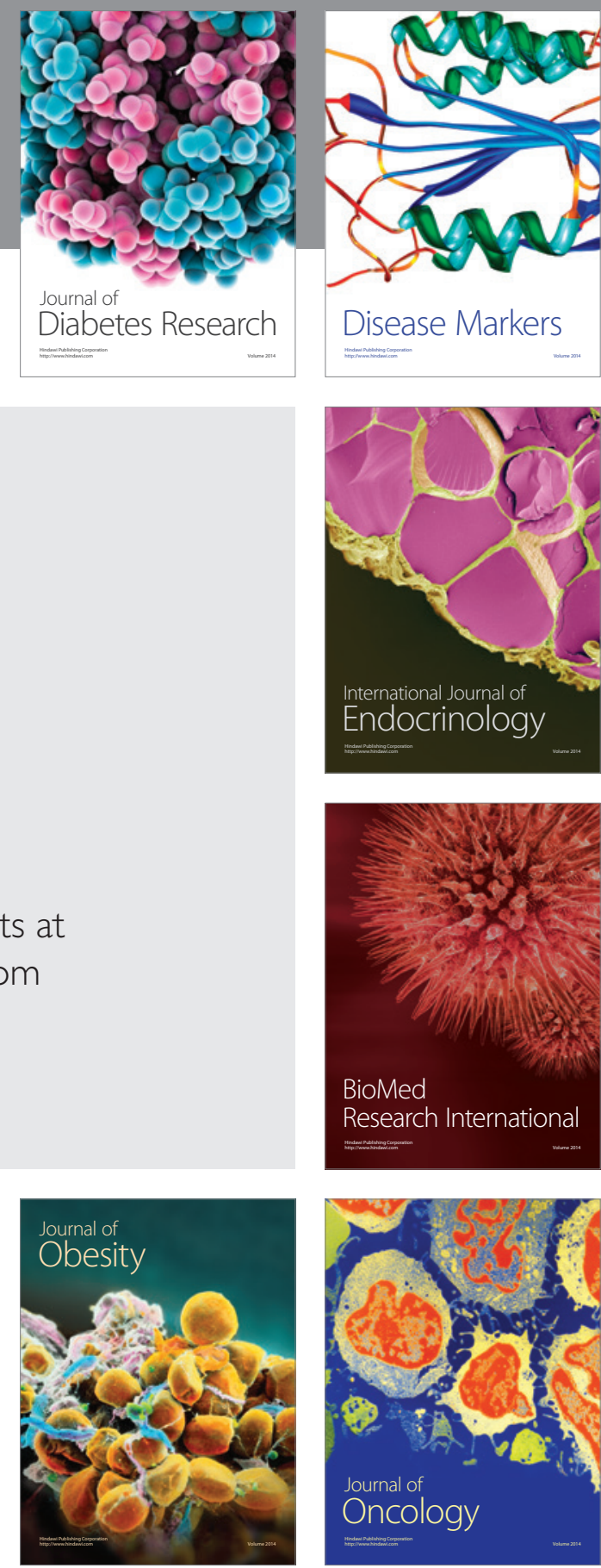

Disease Markers
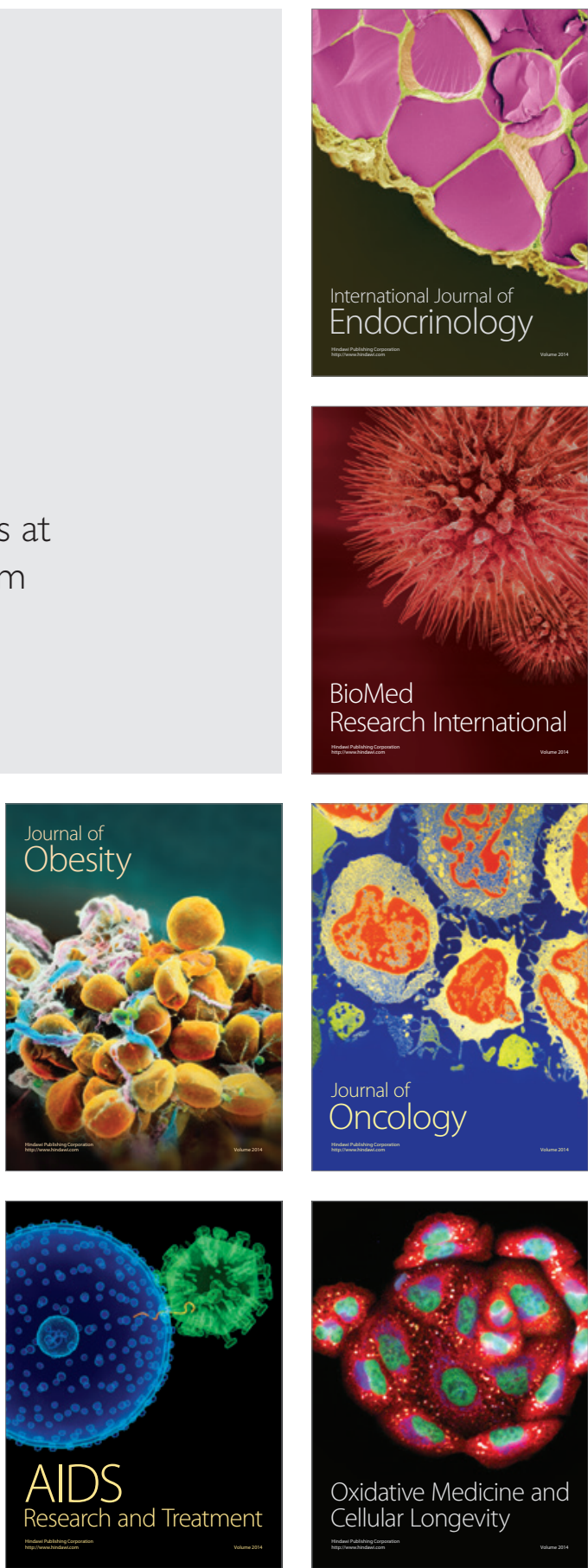